\title{
Ueber und aus Reden von zwei syrischen Kirchenvätern über das Leiden Jesu
}

Translation and Introduction by Pius Zingerle 



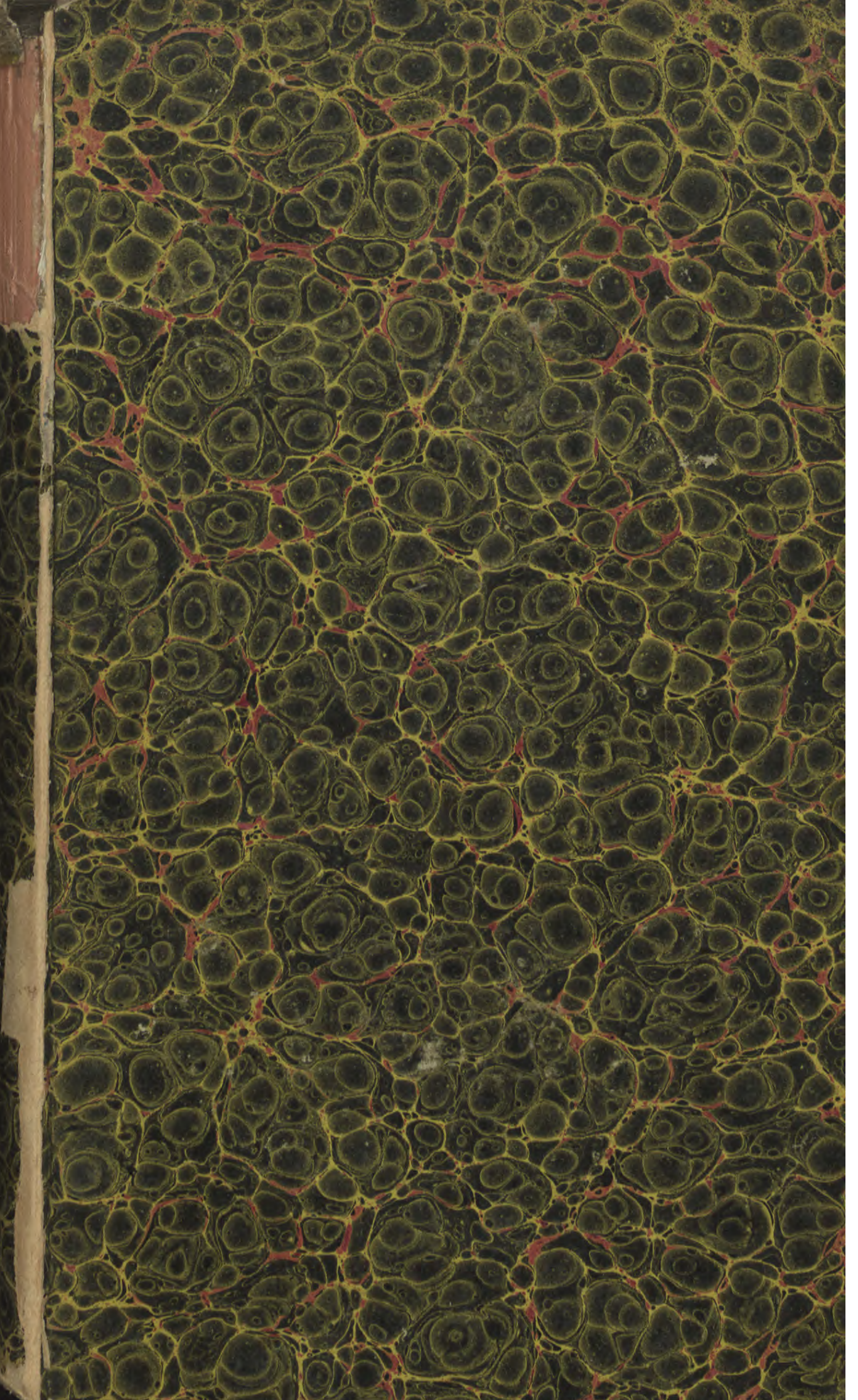




\title{
(e)pologifdite \\ Suntalidurift.

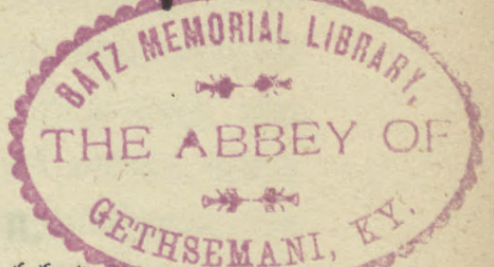

Эn Berbindung mit mehreren Selefrtert

$$
\text { Gerausgegeben }
$$

von

D. v. 㕸ubn, D. Bukrigl, D. v. Aberle, D. fimpel und D. efiober,

Brofefforen ber fathor. Theologie an ber $\Re$. Univerfităt Tübingen.

\section{3weiundfiunfazigiter Salorgang.}

\author{
Erites Duartarkeft.
}

Ểbingen, 1870.

Bertag ber 5ู. \&aนpp'fden Budubandlung.

CATHOLIC UNIVERSITY

OF AMERICA LIBRARIES

Washington, D. C, 


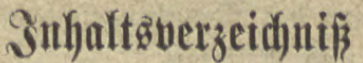

Des

zmeiumbfünfzigften Jabrgangs der theologifduen Quartalidgrift.

\section{Abbandlungen.}

Heber bie angebliche Beränberung bes mafor. Textes รef. 19, 18.

Reinfe. . . . . . . . . . . . 3

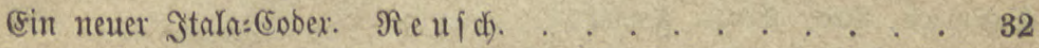

Die Beridjte ber Evangelien über bie 2luferftefung Jeju. 21 berle. 48

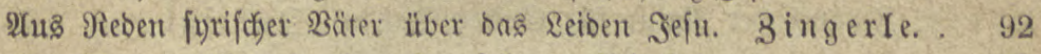

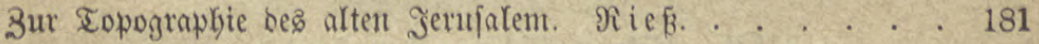

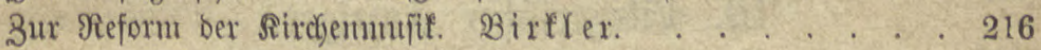
Heber bie Synberefís ber Sdyolaftifer. Safhltel. . . . . . 241

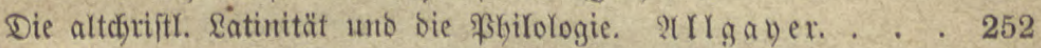
Unebirte Briefe vonl (Serh. Sroote. Nolte. . . . . . 280 Die Geibn. Şumanitätalebren um bie Beit EGrifti. Dtt. . . . 355 Ueber angeblidge maffabäifdje \$sfarment. Sgimper. . . . . 403

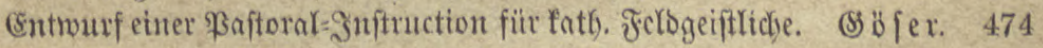
Tertulfian de pallio unt gafy feites Mebertritts zum shriften: thum. Reffrer. . . . . . . . . . . . . 547 Bur nadjerilifden Egronologie. Miargraf. . . . . . 567 Die Snfdurift bes Moab. Rönigs Mefa unt bie polit. uno Relig.

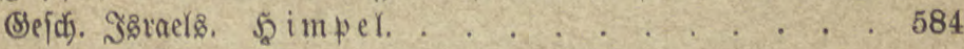

\section{Recentinnten.}

Sdetnex, Prebigten, Beith, Ecibensweg, Dieringer, Raient:

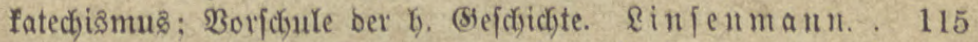
Eifdendorf, The new Testament. FHbexle... . 128 Röldefe, Die altteft. Riteratur. bimper. . . . . . . 130 Rörbefe, Unterfudjungen zur Rritif bes a. Teft. Fimper. . 139 
Ralfax, J̧zrael unb bie Rirdfe, \$impel...... . 161

zobler, Naznreth

Palaestinae descriptiones.

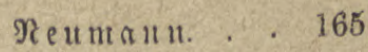

5uber, Befditate des Stiftes Zurznd. Funf. . . . . . 177

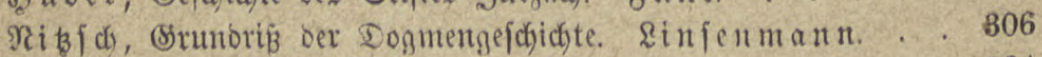

saugrui B, Barth. (Eartanza. ₹uıf. . . . . . . . 324

BB̈bringex, Die Rirdje (5hrifti. Funf. . . . . . . 325

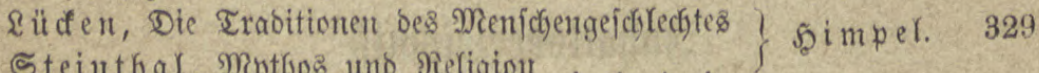

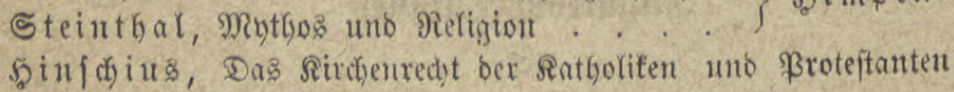

in Deuticjlant. . . . . . . . . . . . . . 496

Sentis, Clementis Papae VIII. Decretales.
Bogt, Rirchliche Berorbunngent für das Bistfjum
Rober. . 535 Rottenbutrg.

23uttfe, Der beutfde Wolfsaberglaube. I sinfenmant. 662

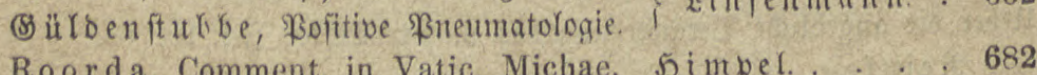
Roorda, Comment. in Vatic. Michae. 5̧impel. . . . 682 Sch wab, Brof. Berg. $¥ u 1 f$. . . . . . . . . . . 691 Danfo, Shlveiter Fantontus. Reinfe. . . . . . 699

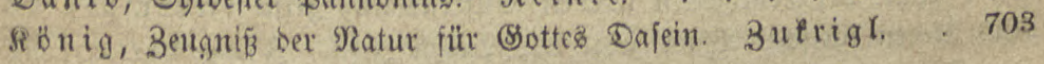

\section{Riterarifdser Anzeiger.}

Nro. 1. 2. 3 am Enoe jebes 5̧eftes. 
4.

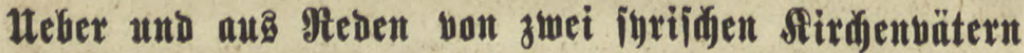 iller bus beiden Seju.}

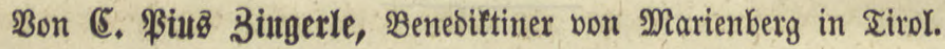

Unter ben vielen bisher nicht Yjerauggegebenen Werfen ber fatbolif(jen itsifcken Siteratur, beren Urtext icf mir in

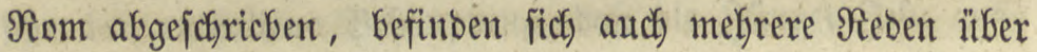
bas Reiben bes Sceilantes und zwar won ben ztwei nach) Ephräm berübmtejten ortbodoxen \&efrern ber fyr. Sirche,

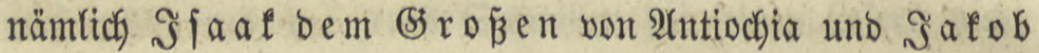

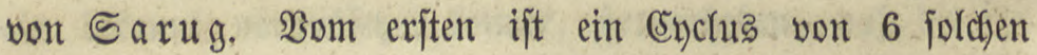
Reben, von bem zweiten ein Syclus won acfit. Beibe finden ficf im I. $\mathfrak{B}$. ber Bibl. Orient. won 2 ffjemani unter bem allgemeinen Titel $\gg$ de Crucifixione Domini« verzeicfnet.

Diefe Reben zwei fo berülymter Scfriftiteller über ben gleichen (Siegenitand wäklte ich mir aus bem Sirunbe zunt 2(bjareiben, um an einem Beifpiele cine 2)rt Farallele bar= zuftellen, wie zwei in ber Siteratur ifyres $\mathfrak{B o l t}$ s lyervor= ragende Männer nach Seijt und Stil verfdcieden ben näm= licken ssegenitano befandelten. Es ift alleroings nun zu Goffen, daß̉ die Werte diejer Männer burch bie volt belt

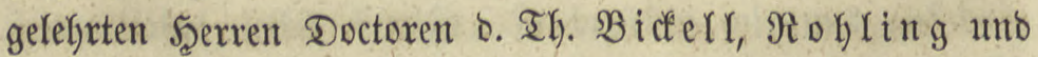
(5) utberlet beantragte Bibliotheca Patrum Syriacorum, 
ein fefr crwünjchtę Unternebmen, in weitern Rreifen betamt werben. Mir foheint es inbés nicfft unintereffant zu fein, went über eine fpezielfe 2Arbeit berfelbent eine vergleichento Uteberfiçt mit gewähiten Proben zujammengeftellt wirb.

WSie bie zmei Mämner ben gleicfjen @toff auf ganz anbere 2 seife fich zurecht gelegt, "um ifgre Bubjörer uno \&cjer zu belegren uno zu erbauen, zeigt fitd) auffallento fdyon bei ber Bergleichung ber Begenftänbe, bie in ben einzelnen Reben betjandert merben. Sjaaf, um bie Meitte des V. Sabrfunberts unter ben Raifern IGeodor bem Süngern und Marcian blüfent, uno um bas Safhr 460 gejtorben, von ben Syrern Doctor und ber Srobe benannt, ftellt in ber

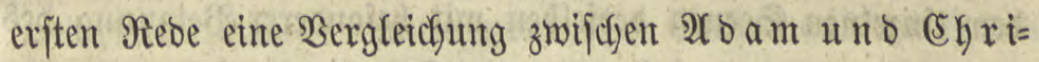
it $u$ s, Eva uno ber Rirche, bem Alten uno Neuet Iefta

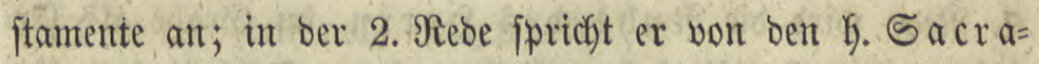
menten als herburgegangen aus ber offenten Seite bes Şeilantoes; bie 3. Rebe bejefäjtigt fich mit ben zwei $\Re$ ä u= bern, in beren Mitte ber Seerr fing, als ben Stybolen

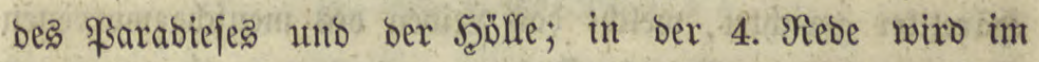

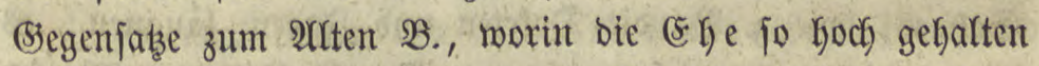
warb, bie sungfraujchaft als Frucht bes Reibens sefu uno Zierbe bes Neuten $\mathfrak{B}$. glänzend bervorgehoben; ber näm=

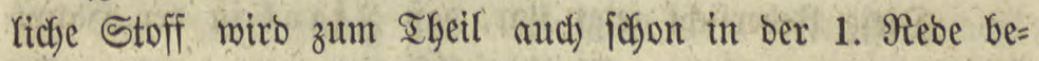
fprodjen, uno in ber 5. Rebe verbreitet fich sfaat noch

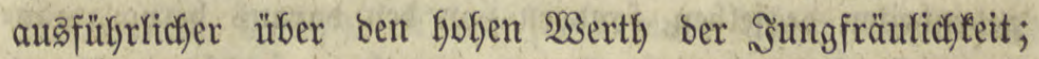

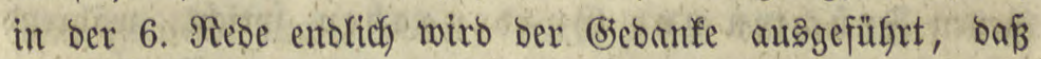
Şejus anjtatt 2 bam's uno (5va's, bie eigentlict) als Schul= bige Gätten Keiben folfen, in feiner Mienfectgeit gelitten, ben Too aubgejtanben, unb bie Scfuld getilgt Kabe.

Salob v. Sarug, nach bem h. Ephräm am Göbjiten won ben Syren gefeiert, int \$. 521 geftorben, hantelt in 
ber 1. Rebe vom Seiben Ehrijti überbaupt uno von ben

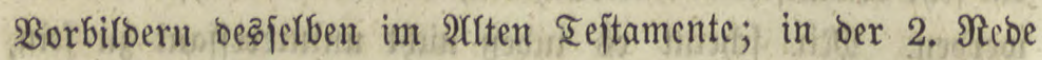

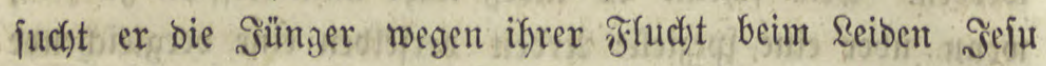
zu entichulbigen; indem or ben (siebanten augfülyrt, baß́ J̌efus arlein leiben uno ben Bater verjöhnen follte; ber britten Rede (Sigenitano ijt bie Berläunnung des Feern

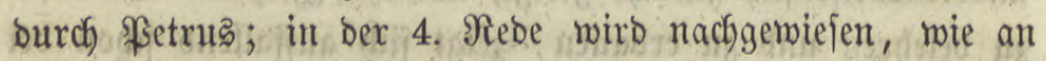
bem (srlöfer die Sorkerjagungen ocr Fropheten über fein seiben uno Sterben genau in Erfüllung gingen; die 5 . Rebe ftellt bie Begnabigung bes belebrten Räubers am Areuze uno feinen Siang zum ßarabiefe dar; Der Etoff bex 6. Rebe ift eine Betrachtung über bas Seiben bes Serrn in ben einzelnen Scenen berjelben nit befonberer Betomung bes Freitags als bes Reibents = uno Jobcstags Jeju; in ber

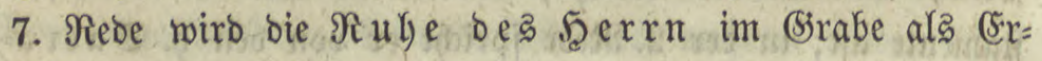
füllung bes Sorbiloes bargeitellt, bas bor Sabbath im alten B. gegeben, und banu die teue burch (Ehrijtuts entitandene Schöpfing gefchilbert; bie 8. Rebe endlich ift gegent bie ફ̧äretifer gerichtet, melche das seiben bę menichgemorbenen Solnnes, wie z. $\mathfrak{B}$. dic Doteten uno suoen läugnen; es twiro barin nachgemiefen, wie nux (Er alş (Sott uno Menich) bie (Ertöjung uno Belebrung ber $\mathfrak{B e l t}$ bemirfen fonnte.

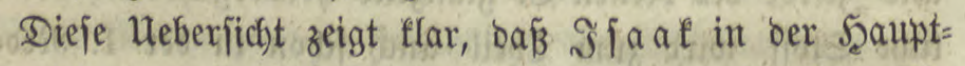
fache nicht vom Seicen Shripiti jelbit uno ben cinzelnen $\mathfrak{B} e=$ gebentyeiten besfelben, fonbern von ben baraus herborgegan= genen ₹rüd) ten un (sinabengaben fpricht, währeno Jatob fich ftreng an's Thema uno befondere Sorfälle ber Reibenägefdjichte bält, bem eigentlichen Stoffe aljo viel treucr geblieben ift.

Die Dar jtellungs weile ijt bei Şaat im San= zen meniger poetija), mefjr räjonnirend uno baher trodener, 


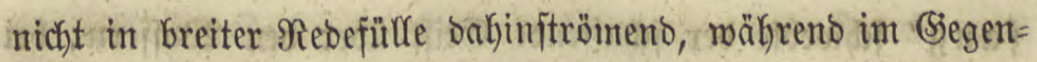
theile Safob fich oft in bichteriche Schjlderung einläß̆t, bie Ecenen bramatifo ausfülyrt, babei jcooch nicyt felten in ben

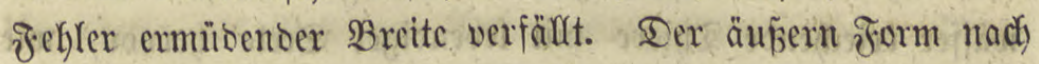

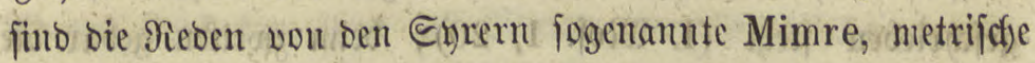
in Einem fortlaufenoe Worträge ohne Etrophenabtheilung,

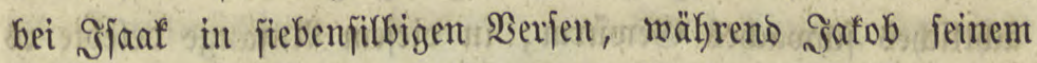
Sicblinghvermaß̄e won zwölf pber breimal vier Enlben treu geblieben ift. \$rebigten in $\mathfrak{B}$ erjen finto alferoing fame, aber bei ben Eyrern bielbeliebte Rebeform.

Nach) biejen allgenteinen Borbemerfungen will ich bie

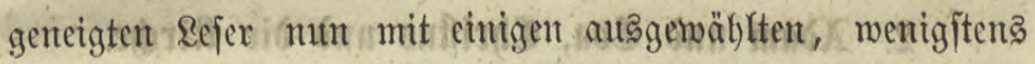

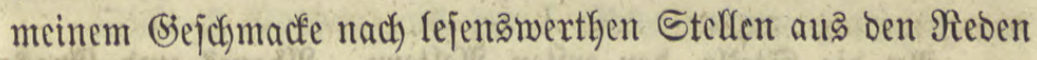

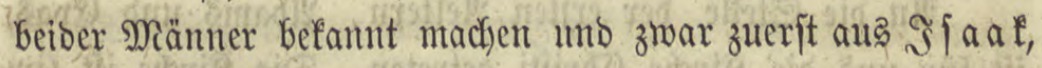
weil er ber Beit trach früber lebte.

AU

\section{Das soppelte "Im Anfauge." \\ (I. Mof. 1 unt Sof. I, 1.)}

3weimal funben wir bas "im 2 infange; jentes, wo

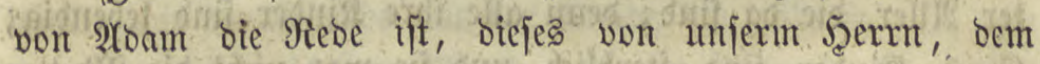

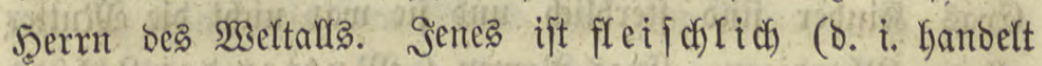

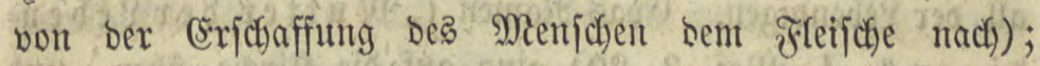
biejes ift geiftig (won ber neuten Schjopfung in Ehrifto. II. Rorintf. 5, 17). Durcf jenes warb 2(bam n(s Menich) bem fileifche nach gebilbet, Durch biejes bilbete unfer Sperr Dab geiftige Ebenbito um. Bei jenem "im $2 \mathfrak{A} n$ fange"

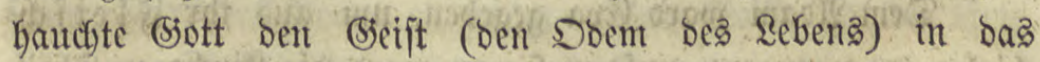
Ingeficht bes Mienjicjen (I. Mof. 2, 7); bei biefem "im 2) $n$ fange" Gaudbte unfer Şerr feinen Süngern ben (bet= ligen) Beift ein. (Jof). XX, 22.) Bei jenem (im $2 \mathbb{n}=$ 
fang" fanebte ber faffaffende (Seijt über ben Waffern; bei biejem jobrobte ber h. (Seijt über bie Iaufe herab (Matth). III, 16). Beim exiten "im 2 nfang" Grachten bie (Sie= mäffer friectjente Thiere mit lebenoiger Secle herbor, wie gefdrieben jtebt (I. Niof. 1, 20); beim zweiten gebar bie Iaufe Menjchen. Şm 2 nfang erzengte bas Waffer ver= ächtliches jaymaches (Sienürm; in biefem 2(nfautge belebte es Seelen, bie burch Sünben geftorben waren. İ $\mathfrak{A} n \mathfrak{f} a n g$ erbielt 2 roam einen untermorfenen Sseift; beim zneiten "im

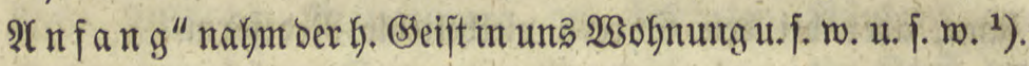

\section{X(dam und Eva, Chriftus und die fardhe.}

An die Stelle ber eriten 2Yeltern, 2roams uno Evas, ift für uns bie Rirche Efrifiti getreten. Die Rirche ift (im

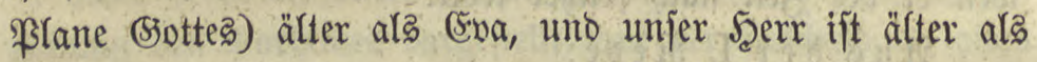

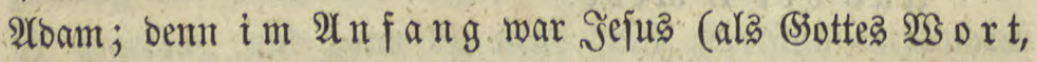
ber Logog. Sof. I, 1), uno ef' er noch exicfien, war ex

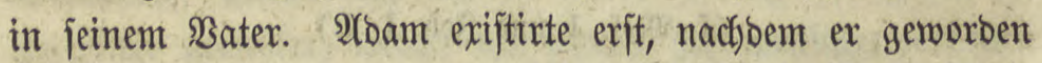
mar, uno zuvor war er gar nicht. Die Rirche ift bie Mut= ter 2ruler, bie ba fint; benn alle ifgre Sinoer.finto lebendig; (svas Rinber find fterblich und fie war nicht bie Mutter all ber Rebendigen. Svas Namen ("Mi utter ber \&eben= oigen." I. Mof. 3, 20) ging auf bie Rirche über, uno Yloams Name auf unfern Errïfer (als ben zmeiten Sloam. I. Rorintf. 15, 45-47). So waren in Mloam utb 5va bie (Sebjeimniffe ber Rirche und unfers Şerrn vorgebiloct.....

Dem 2 toam waro Eva gegeben, um aus ifr Freifat)= lich e zu erzeugen; unjerm Şerrn marb bie Rirche zu Theil,

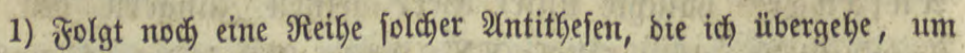
nicht burç) Einförmigfeit bie \&ejex zu ermüben. 
um aus ifr (Seiftige herworzubringen. Dem arbam warb

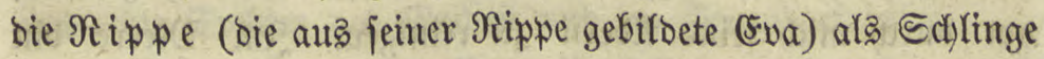
zum Berberben ber Menlichen segeben, unjerm Şerru aber

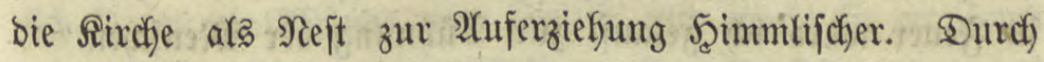
2romes Soos fam Eva als Miutter ber Streitfiuctitigen her= vor, unb burdy bas \&ov? unfers Şerrn bie Rirche als Mutter Der Sanftmüthigen. Baflreid) fint Evas Sinber, uno ifre SBiflen fitto vielfact); bie Sinber ber Sirche fino (Eimb, uno ibre Berjammlungen baben uur Einen Biffen. Eva gebar zwei Brüber, berent einer bell anbern erfcklug; Myriaben hat bie Sirche geborelt, und in ifren Sepinnungen baust fein Sroll u. f. w.

Dieje 2 Proben aus ber I. Rebe mögen genügen, um

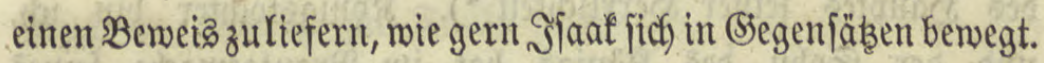

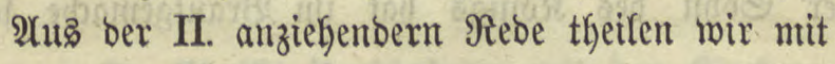

\section{Den Eingang:}

Ssebeimniß̄oulf redete ber (Sifnube mich) an, rief mir zu unb fpract): "Erfüffe beinen Muno mit verborgenen Bebeim= niffen, ziche bann aus, uno prebige ben Menjchen!" So wintte mir ber (Slaube mit ber (Snabe, ich) näherte mich) ifgm uno er that mir ben Muno auf uno fanbte micf, feitre Seerrlicheeit in ber $\mathfrak{S e l t}_{\mathrm{f}}$ befannt zu machen. Sich fragte ibn: "פBie bift bu befchaffen, auf baj ich fagen fann, wie

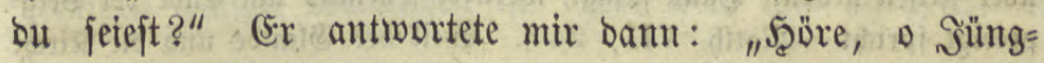
ling, int weldyen Mityterien ich gefunten werbe! 2(ub bem

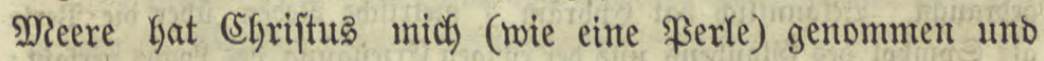
feiner berrlicken Srone eingefïgt. Bom Beijte bat ber (Erjt: gebortie mich als Beute genommen ${ }^{1}$ ) uno in feit febenoinges

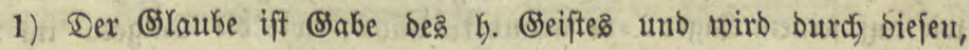

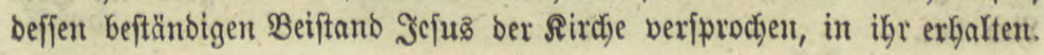

Egeol. Quartalidrift. 1870. §eft I. 


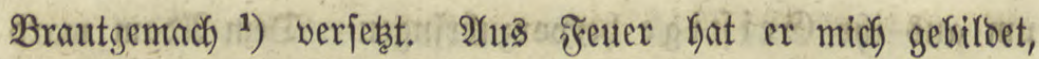
um burdf mich feine 2tbent zit reinigent. Sim Meere bin ich geboren, utto it meinem Sinnern wolgnt ber (Beijt, uno in Feuter waro ich getauft zur Süfymung ber Menfchen."

\section{Die fairdbe und die b. Sacramente.}

Die Perle ift eine Iachter bes Wafferb, bie Iodhter bes Seiftes ift bie arglofe Taube (bie Rirche. Scoh. \&. II, 10. 14. V, 2. VI, 8). (sin Sokn bes jeuers ift ber 2(sbejt ${ }^{2}$ ); bic Iochter bes Richtes ift bie Sirche. Im Meere verjinte idf nicht, burdh ben (sieift wero' icf nicft erj(c)üttert ${ }^{3}$ ). sich bin bie Rirche bes lebenoigent Eritgebornen, bie Stübe Des Scauptes feiner Seerrlichfeit ${ }^{4}$ ). Rönigstockter bin idf), tulo ber Solhn bes Rönigs bat in Brautgemache feines

1) Das leben= ober Keirfpeitbenbe Brautgemach) Deş Sgeilanos ift bie Sirctje, in ber fein (seiff immerfort weilt und wirft. Dab for. Woort

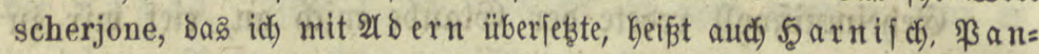
zer. Bezieft bas "feine" fich auf Brautgemady, fo find unter 2 bern mofl bie Sslieber ber Sirche zu berftefen, fo wie audd, wein "feine"

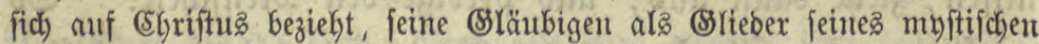
\&eibę.

2) 2 mi ant dober Bergfflactje. Ephräm nimunt bas $230 r t$ im weibr. (sefdil. unb fagt "Ẽ Dd tex b. F." u. f. f.

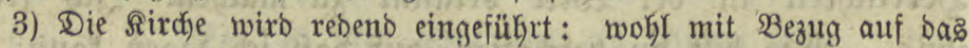
über Feeffen gebaute Şaus gefagt, worilber (SGriftus am Enbe ber Berg: prebigt fpridst. Matth. VII, 24 f. SBseir ber (ST)

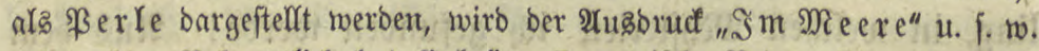

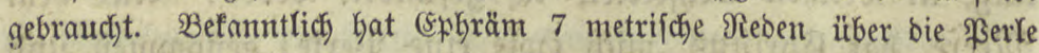

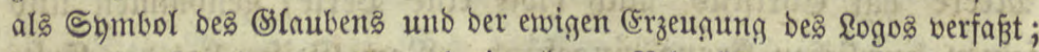

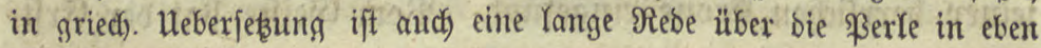
Dem Sinte übrig.

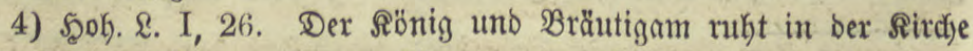

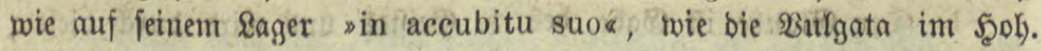
Rieb kat. 


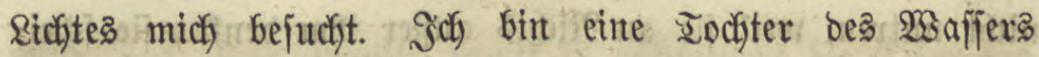
unto eine Iodjter bes Bseiftes und im Feuter getnuft.

(E) Bares Feuer ${ }^{1}$ ), trinfbarer (seift ergeust

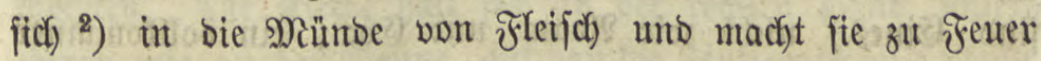
unb (seift. Heber ben Waffern (Der Taufe) wohnt baß Feuer unto im Fener wirlt mächtig ber Bretift. Werichiebente Sräfte finto mit ber Silfyung ber Taufe verbunben. $\mathscr{D} a \mathfrak{b}$ Waffer löfcht bas Feuer nicht aub, und bas Feuer verzebrt bas Waffer uicyt. Der Bseift verwirrt beibe nicht, weil in affen breien (sine Rraft ift. Weer baburch nicht getauft ift,

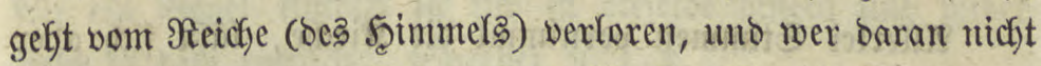

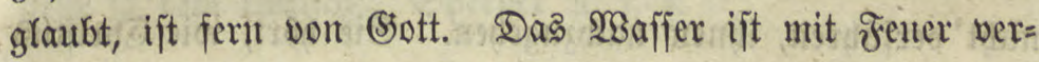
mijayt uno ber Beift mit biejen beiben, unto in bieje brei jteigt ber Mentich zur Iaufe Ginab.

\section{Chrifti Đerbindung mit Der \&ird)e.}

(Efriftus verbanto fich mit ber Rircte uno vereinte fich ganz mit ifrr. So fint fie Eines gemorben, wie gefdrieben

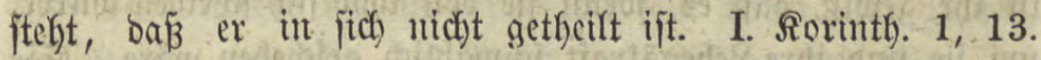
Sie faum ign nicfst verlafjen, weil fie burch ben Beift mit ifhm vereint ift. Sie will fich won itsm nicht entfernen, weil ify Blut mit feinem Blute vermifost ift. Sie trent fich nicht von ber (sintrad)t mit ifym, weil ibr Rebent mit bem feinigen innigit verbunben ift. Sie nirb ifm burch) Sinde

1) Unter biefem Bilbe ftellt auch (sphräm bie (Eudjariftic bar, z. B. in bem X. Eejange contra Scrutatores.

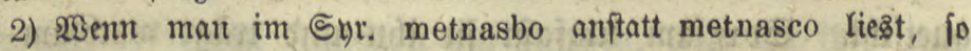
fommt ber paffende Sinn Keraus "wirb von Münden empfangen ober genofifen." Die Butuffaben Beth uno Coph fino im inrifa).

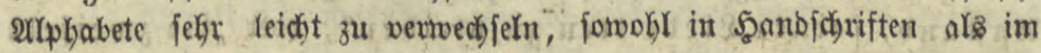
Drute. 
nicht untren, weil fie an Nichts auß̄er ifyut benlt; fie fochei=

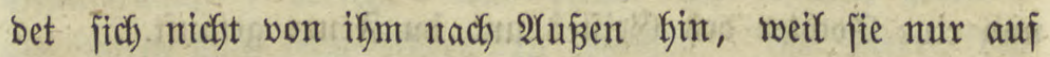
ifn iffen Sinn gerichtet bat. Die Rirche uno unfer Scerr find Sines, nicht wie Srbam und Eva; cin volfeommner Menjch find fie, weil Einte Seele in ifynen ifjt.

Die britte Rebe beginnt mit einer fobonen Daritelfung

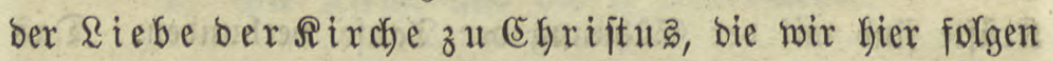
raffen:

\section{1.}

2rflerlei Stimmen wernimmt bie Rirche, läß̄t fich aber nicht verfübren, ilynen nactzugehen. Sie bört, wie Bhriftus sejchmäht miro; alfein jie zmeifelt in $\mathfrak{B}$ ezug auf feine Riebe

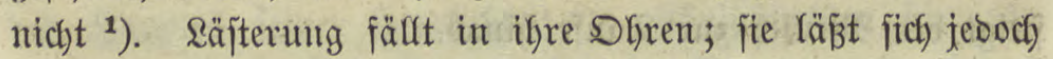

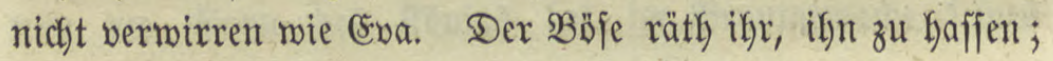
fie lingegen achtet nicht barauf und tritt bie Ratbjchläge

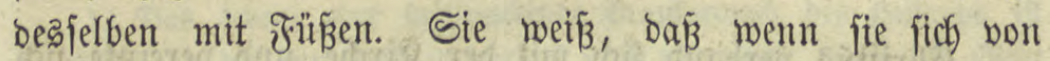

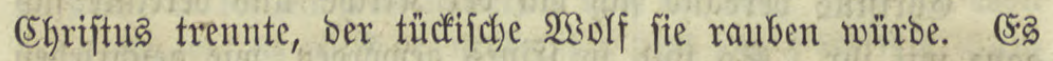

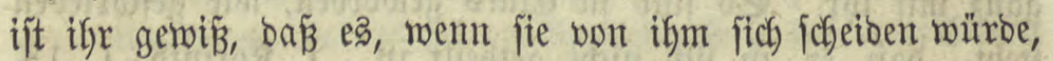

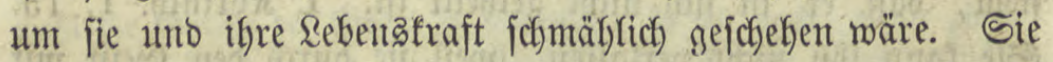

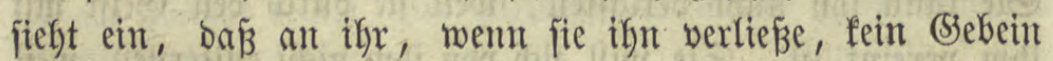
mehr am anbern häugen bliebe. Sie ijt fejt überzeugt, baß́, menn fie ifyn haste, für ihr (Sefchnür fein Sceilmittel mefyr märe. Sie glaubt ficher, baß̉, wenn fie ifn verläugnete, bie vonl ifgr getöbtete Echlange fie töbten wiltroe. Darum bält fite an ifym wie an einen alnfex in ifyrer Seele feft, bamit

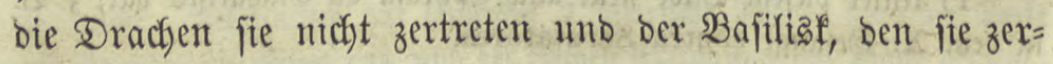
queticht. Gorgfam umfañt fie iful mo trägt machfam fein

1) Doppelfinnig, wie mix fajeint; entweber "fie nim mt feinen 2tnftanb, feiner siebe treu, zu bleiben", ober "fie zweifelt an feiner siebe zuibr nidt." 
Birb auf ifyer Bruft, bamit ja nidyt mefyr bie Dämonten, welche fie burch feinen Namen vertrieb, fict) ant fie lyängen mëchten. Die Sirche raält fich an ber reçten Şano unjerş

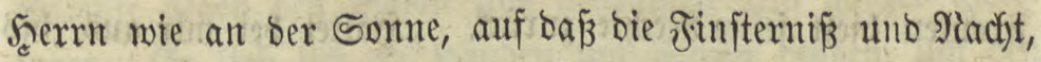

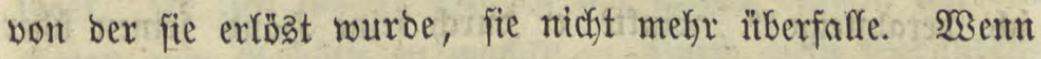
baut bie 2(Gtrünnigen ifgr fagen: "Schan mur auf feine Dornen!" fo wirb fie zum $\mathfrak{B o ̈ g e l e i n ~ u n o ~ v e r b i r g t ~ f i c h ~ i n ~}$ benferben vor bem Şabichte. Sie fefämt fich) feiner Dornen=

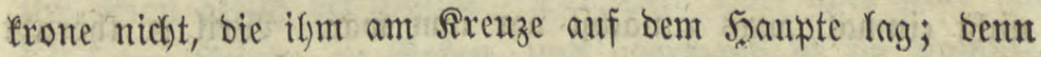
wie ein $\mathfrak{B o g e l}$ flïchtet fie ficl) in biefelbe ljinein unto miber= ftelgt fo bem tïctifchen Sperber u. f. f.

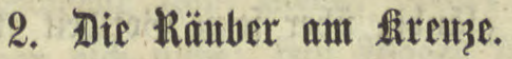

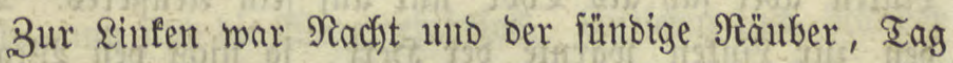

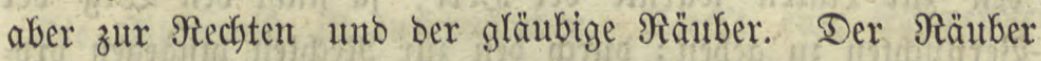

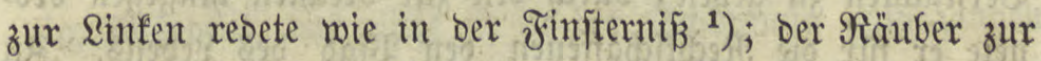
Rectiten werherrlichte (Jefum) als ein Solgn bes Miorgens. Der Sinfe webzte wie in ber Radjt fein Wort zum Miorbe, Der Rechte manbelte als Soljn bes sichtes ben 2 seg ins

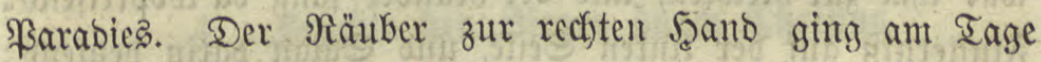
ben geraben $\mathfrak{S e g}$; bas Rino ber Nacht aber zur linten Seite irrte auf pfablofem 2 (bwege herum. Der zur Rechten fprad) als Sinb bes sichtes: "Şerr gebente meiner!" Der zur Sinfen jeboch als Berfinjterter: "Steige berab, rebe uno erbalt' auch) unts am Reben!" 3 feiner sinten ftellte ber

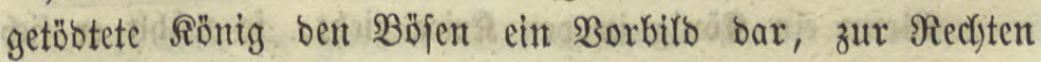
aber gab er feinten süngert ein Beicfen, treu bei ibm all

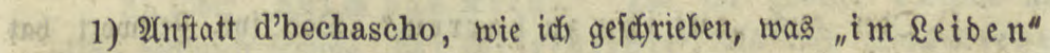
heirst, glaube idif d'becheschko rejent zut follen, wie ber Begenfał forbert. 
zubalten ${ }^{1}$ ). Bu feiner $\Re e c h t e n$ Gielt er bie Fliefyentbelt

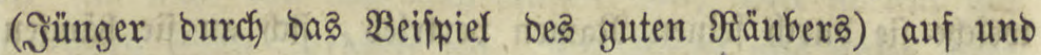
ermuthigte bie 2Apoftel. Die burdi feine $\mathfrak{B e r f o l g u n g}$ Zer=

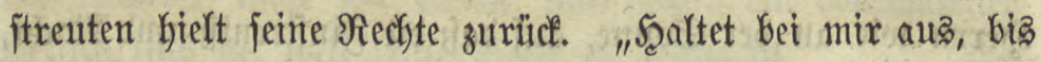
id) Jerabjiteige!" wintte er burdh feine şanb feinen über Das Beftetgen bes Sreuzes beitürzten S̈üngern zu. Der zur

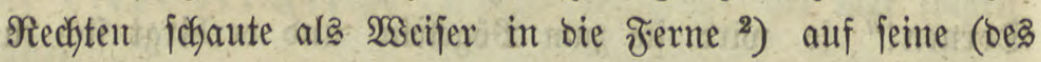

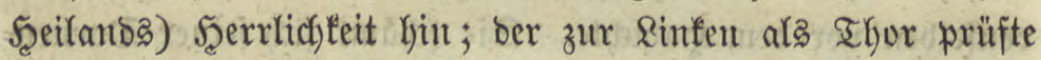
niç)t einmal, wab zunächjt wor ifym war. WBeil er thöricht mie ein Brübler mar, zlweifelte er an ber Wahrbeit, während

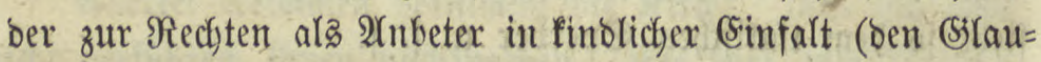
ben an Šeju (Sottbeit) befannte. Der zur rechten Seite war als entjchieben gläubig über feine Bsottfcit erftaunt; ber zur

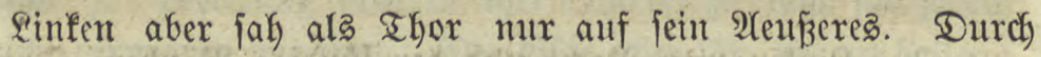
ben zur sinfen warnte ber Seerr, ja nicht ben $\mathfrak{B}$ eg ber Berflucbten zu geken; burch ben zur Rechten bingegen oro=

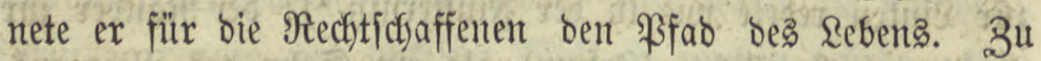
feiner Sinfent twar bie Fejfle, unto ber mitten in igre Gerr= jajente BB̈je warb zu Echanten gemadt. Dab Parabies

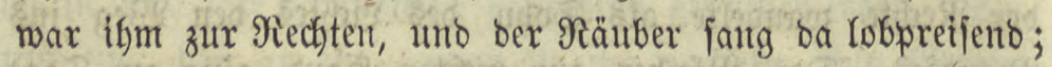
Finiterniz auf ber linten Seite, unb Eatan barin Keulent;

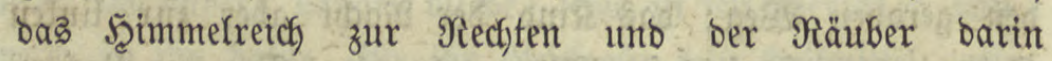
meitent. ......

\section{Chriftus als Sieger Dutdh das ferew3.}

Wenn ein Rönig in ben Rrieg zieft, fo wählt er fich

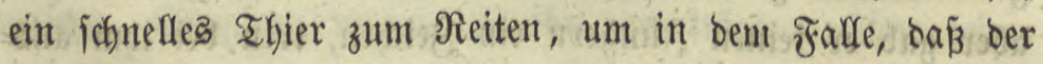

1) Dober audy "aufihn zu haxren." Das fyr. Beitwort bat beibe Bebeutungen.

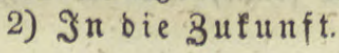


Serfolger übermächtig brängt, ficf wor bem Tobe zu retten,

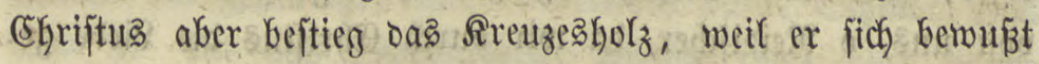
war, 2(thes zu überwinton, Berborgen ${ }^{1}$ ) erfob er fich zum Rampfe gegen ben Satan unb vernichtete fein ganzez Syeer=

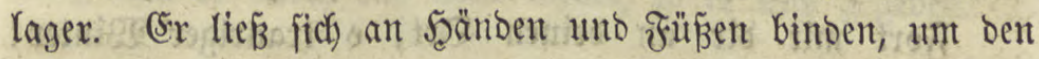
Satan zum Befpötte zu madben. "Ourd mein (sebunbent= feil befieg' ich bich, uno burch meine STreuzigung töbte idf bich" 2). (Egriftits Katte wie Samfon gejdylafen, ba feffelte ifn Sion gleich) ber Dafila. Der Feeto marf aber feine ifn feffechiben Feitto S Befreuzigter wie beleno bijt bu! Dutrch bidf mard bas Szeerfager bes Wiberfachers veridjeucht utho zermarmt. Dir fommen Schulfe nicht zuvor, Sieiter bolen bich nicht ein uno erjagen bid) nicht; feil Wagen loumt bir zutoor.

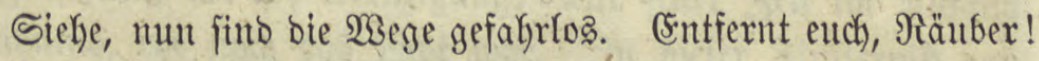
Die Finfternís ift entjchmunbent. Stecl't eure Schmerbter ein, Miöroer! bas Richt ift in ber Schöpfung aufgegangent. Biebt rubig in eure Staot, o Pifger! Satan ift über= munben!....

\section{4. friid)te Des Sieges Durdb Clyriftuts.}

S I00, ftïrze bich 1 tm in bein eigen Schwerbt, weil (5Griftus von ben Tobten auferitanden ift! Flieke von uns, - Satan! Denn ber Friebe ift burch ben (Siefreuzigten ${ }^{3}$ )

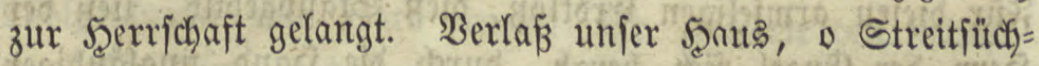

1) Weir bie göttlidje Natur unftcttbar mit ber Menfdigeit ber= bunben war.

2) Worte Ehrifti an Satan.

3) Socr "Dut d) bas $\Omega$ reuz." Die inr. Wörter z'kipho uno zlibo bebenten fowobl "ber (Sefreuzigte", abs auch "b as areuz." So an vielen Stellen. 
tiger, weil uns Serföhnung zu Theil geworben! Weiche won uns, o Reibifcher, ba wir ourch Egriftus bie Riebe ge= wonnen haben! (Entferne bich) von uns, o Mllverjöämter! Wir fino ja burch ben (sefreuzigten feujd) gerovrben.

Fort mit bir an beinen Drt, o trauriger Winter! Denn ber heitere Frübling ift gefommen. Entferne beine Nebel uno Wolfen, weil bie Sonne in unfern Sänoern auf=

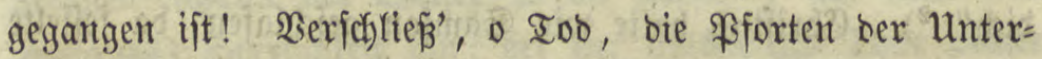
welt, bamit Niemand mehr Ginteinfomme! Weil ber Sarten

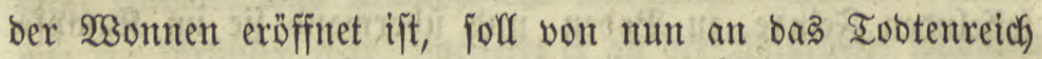

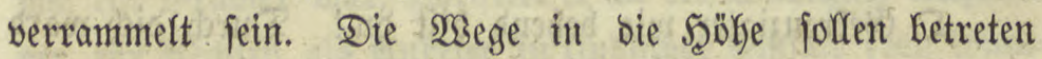
werben, bamit bie Sterblichen bahin emporjteigen. In ber

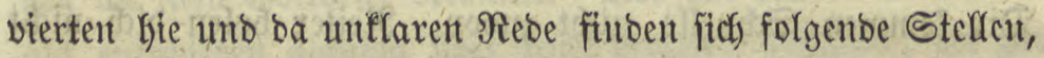
bie mir fjer ber Mittbeilung nicht unwürbig forfienten.

\section{1. (Jottes Liebe gegen die Alten/dhen.}

(Sott gab feinen Sobn zum Iobe hin, um bas Scmupt feiner Schöpfung nicht zu (Sinunce geben zu raffen. (5x überlieferte feinen Erzeugten dem Sreuze, bamit ber Staub nicft Urjache babe zu murren. Dié̉ ijts, mas feinten (bes Menjchelt, bes Staubgebornen) Şerrn in feiner Erbarmung

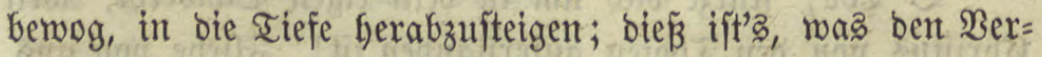
borgenen erregte, herabzutommen uno Mienja zu werben.

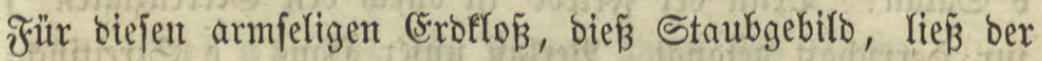
Şerr ber (Engel fich Kerab, burch die Şand ungläubiger

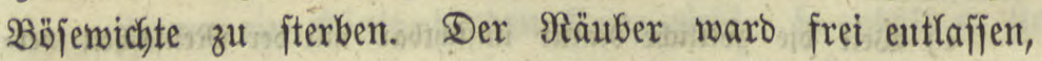
uno fein Seerr an's Sireuz gebeftet. Der ba Böjęs verübte, entfam uno blieb angeptört, wäbreno ber sute ftatt feiner

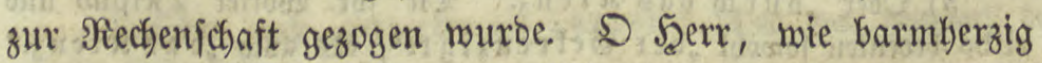
bift bu! D Schöpfer, wie bift bu fo bemüthig! Dein 


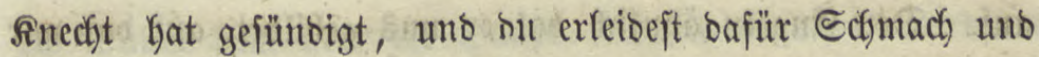
Too $\left.{ }^{1}\right)$ ! Um bas Tobesurtutbeir, welches (5ott über 2roam ausgefproctjen, aufzulöpen ift fein Yebensiger Eobn gefommen. Dießs that er burch bas nette Bebot, fo er und gegeben.

\section{Die unte \$djöpfunt Dutrd (Cljriftus.}

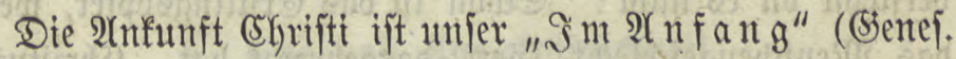
I, 1); bas Scaupt unjers (bes neuen) Bejchlect)tes ift (bott. Unjer 2rbam ift unfer Fुerr; ber Sauerteig unjers Stammes ift beilig (ooer "ber bुeilige). 2(lz fie ifhn frenzigten,

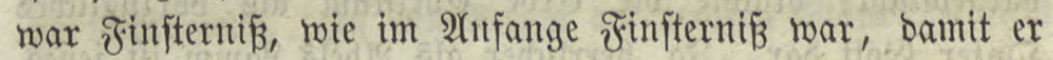
bie Sdjöfung nell umichaffen fönnte. Dieje Beit (ber

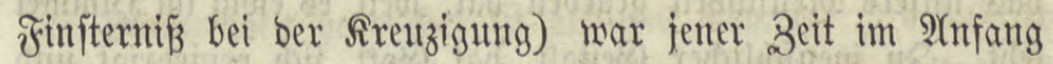

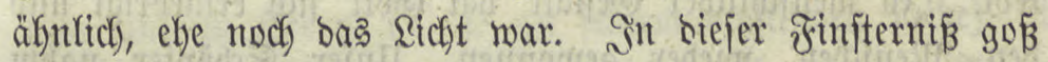
Erfriftus wie in einem Schmelzofen bie Schoppfung um unb madjte fie alts einer alten uno wilftent zu einter neuen feits gebilbeten. But einem neuten Bsebilbe biloete er $141 \mathrm{~s}$ unto maçste unß fähig Şeiligleit zu geminnent. Err formte unfer (siefclecht ofne Eauterteig um, um uns in bas santo ber Şeiliget zu verjeţen......

2roams Sauerteig war geidymadtlos gemorbell, ber Menich war verborbent ${ }^{2}$ ); er war alt genurben utto in's Berberben gefunten; alleit burch (Ehriftus befam er mieber

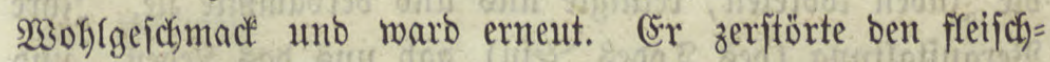
lichen Menjchen, unt baute ifhn als reinen geiftigen wieber

Tiif 1) Bergletche Meditat. S. A ug ustini Cap. VII: „Peccat iniquus et punitur justus. Delinquit reus et vapulat innocens. Quod perpetrat servus, exsolvit Dominus! Quo, nate Dei, quo tua descendit humilitas! etc. etc.

2) Dber "f a be geworben" wie Salz obne Mraft. 
auf. Den Engeln ähnliç hat er unz gebiloet, auf bá̉ wir

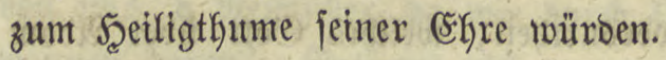

\section{Chriftus als (Dpfer.}

Sit wohf bein Sim barauf gerichtet, o Echuller, ober verjterjit bu es nicht? Echön ift bas Erittingäopfer, melches bas Menfchengeichlecht (Sott bargebracht hat. Ehrijtus iit bas aubertejente Dpfer, bas bie Eroe Bott gegeben. 29re ftatt bes Sammes, meldjes 2Xbel von feiner Seerbe Bott bargebracht, brachte bie Errbe Egrifitum als vorzügliches

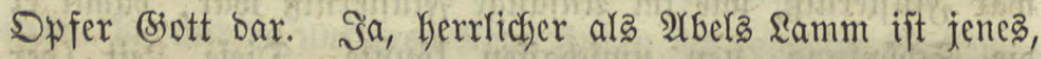

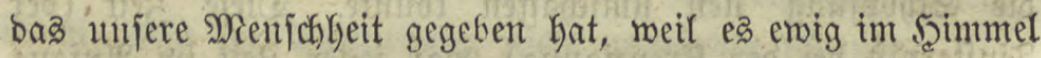
rebt. In menichlicter biejtalt bat (sott fich erniebrigt uno ben Menichen wieber gewonnen. Hnjer Erföpper nahm Sinechtsgeitalt an (PSgilipp. II, 7) uno fam auf bie Erbe. Der Unfichtbare waro vollemmener Menich unb trat in bie Sichtbarfeit. Durch ben Bactenjtreid), ben or im (Serichts= haus empfing, befreite ex, ber bie Menjchbeit zut erlöjen gefommen war, ben Menjchen aus ber Sflaverei, morin er Dem Satan biente.

Diejes Samm, welches bas Bolf fammelte, verjammelte uns unt zeritreute fic (bie Suben). Das Ralb ${ }^{1}$ ), weldjes bie Suben töoteten, reinigte uns uno verbammte fite. Stre Seranitaltung (bes sodes seju) gab uns bas qeben, unb

1) Drientalifd) mintor auffallendes Biłb (Skrifti als Dpfers für

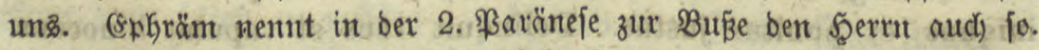
(Es ift 2nipielung auf bas Maftalb it ber \$arabel vom verlornen

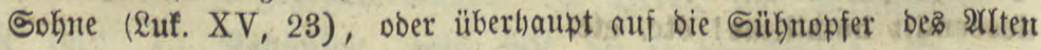

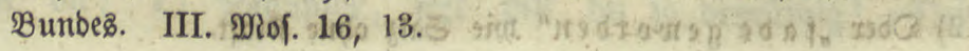


bie Sünbe fam über ifr F̧aupt. Durd) biefen (Ermvrbeten fint wir verföhnt morben; wont ifnen aber wirb für baß

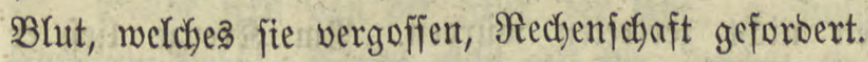

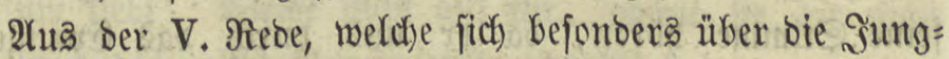
fraujchaft als frucht bes Sreuzes verbreitet, heben wir fols genoe Steflen aus:

\section{Ehge unt Iutgfrüulidjkeit.}

Whir verwerfen bie (she in nicht; bent fie ift eine foboune

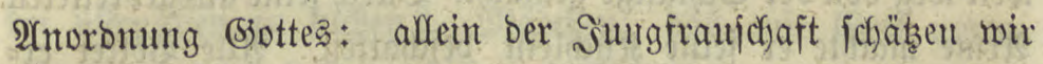
fie nicht gleich. Sin ben 2lugen ber mafyren (Släubigent ftefyt

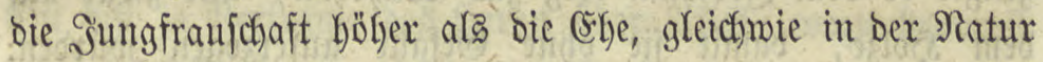
bie Sonme weit herrlictjer ift als eine Sampe. Sebces Silied bon unjerm 5̧errn (o. i. an feinem myjtifdsen scibe) ijt ein ganzer volffommer Mant (ङ aber find Miann unb Weib, bie beun Ein Rörper werben.

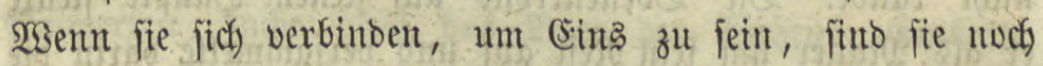
vom freifche, uno biés ift mur ein Iheil bes geiftigent Mien= fchen. Die unferm Seerrn angekören unto fich mit bem Keil. (Seifte verbinden, finto burch) Reintheit bem Reibe uno (Seifte nach geiftig. Durch bie Sumgfrauf(haft vereinigen fich Rör= per und Beift und werben Eins.... 2lbam ijt ber Sater Der Entzmeiten, umfer Şerr ber Bater ber Bolfeommenen unt Şeiligen.

\section{Das fareur als $\mathrm{A}\left(\mathfrak{y l} \mathfrak{l}^{1}\right.$ ).}

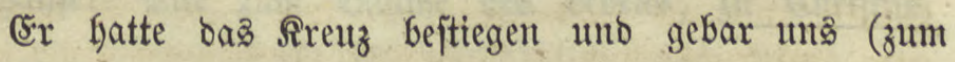

1) Mit Beziefung auf V. Mof. 32, 11 uno Matth. XXIII, 37,

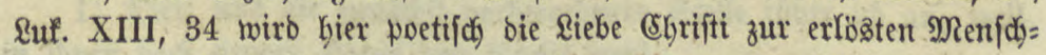
beit mit ber \&iebe eines $\mathfrak{B}$ ogels zu feinen Suntgen verglidjen. 


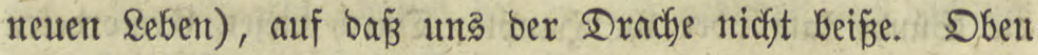
auf bem Scolze lagerte er jeine Sungen ${ }^{1}$ ); bamit fite won ben Füchfen nicht zertreten würcen. 2(m Areuze ließ̧ er feine Stimme bören, ba er uns burch bas Evangelium zeugte. Die Schmerzen exgriffen ifnn auf bem Selze, als er uns zur Wafhrbeit gebar. (Ex frümmte fitc) (beim Neigen bes Seauptes im Sterben) uno gebar uns auf bem (Enpref= jenjtamme, damit ber Bafilią uts nicht verberbe. Wie ber Storch auf dem (Sipfel ber (Seber hat er aud unfer Rejt weit weg von ber Echlange gemacht. Durch feine ausgebreiteten Ulrme machte ex feinte Sächlein bejchatten. Alfe $\mathfrak{B o ̈ l f e r}$ er= zeugte er vom Sirthum weg zur Wafhrfeit, uno zwar auf bem F̧orze, damit fie ofute Befahl altferzogen mürben.

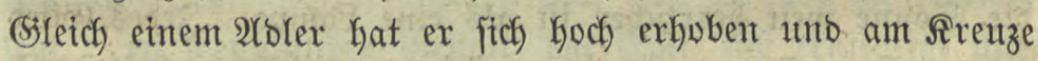
unb wie auf einem Felfen geboren. Nuch bat or fein Nejt mit Dörnern umgeben, auf baßj ber Eperber feine Sungen nicht rautbe. Die Dornentrone auf feinem Şaupte ftellte er als Mauer um fein Nejt auf und verjammelte barin bie 3 ëlfer, welche er butch feine Reiben wiebergeboren, bamit fie rukig barin weilen fönnten, nicht aus bem sejte berabge= worfen würben, ber Sperber zu ilynen nicht einbränge uno

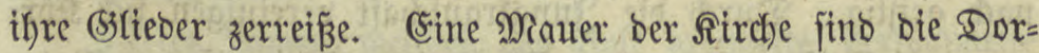
nen uno wie ein $\mathfrak{B}$ getein wohnt fie barin. Drauken aber fchwärmen die গaubvögel herum, fommen aber mit ifren Srallell nicht Ginein; benn bie Dornen find eine Schuts= webr bafür, uno ber Speicher feites 2Antlizes bient feitter Brut zum Bsetränle u. โ. w.

1) Doer "froden feine şungen a 


\section{An sinte juntgfräılidge Secle $^{1}$ ).}

Bleite fern von ber frur ber Ekge, S Jungfrau, bie SGriftum liebt! Weibe niçt auf ifr, bamit fie bir nicht f(c)abe uno bicf nicjt Bebrängniffen preiägebe!

D Bögetein, waß hajt bu mit bein Sperber zu thun, bu Schutbloje bei bem গäuber?

D Samm, was hajt bu mit bem 2 olfe zu fichaffen, bu $\mathfrak{A}$ rgloje bei sem Feeimtüctijctjen?

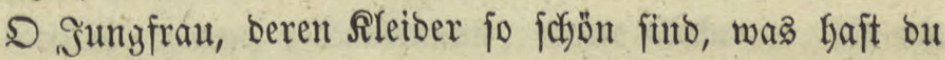
bei Menfchen zu fuchen? Mäbchen, bas mit Bott umzu= geben hat, was hajt bu bich) mit Mänuern zu unterfalten?

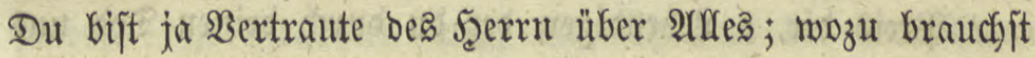
bu mit Sänglingen bich abzugeben? $\mathrm{Ea} \tilde{\beta}$ boch von ber neten $\mathfrak{B a f y n}$ nicht $a b$, won ber bie sugent fo leidyt binab= finft! Sime nach, wantole ben $\mathfrak{S s e g , ~ b e r ~ a u f w a ̈ r t s ~ f u ̈ l y r t , ~}$ mo fein 2lnitoß ijt! Weibe boch nicht auf bem Boben ber Sctmerzen, fuche nicht bas Brod ber Wehen! Enthalte bicf bom Brobe, bas die Zähne uno ben Muno ber es

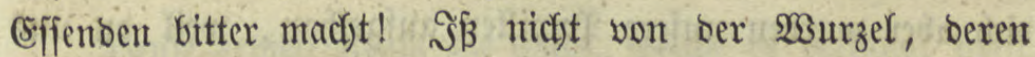
(Ssefchmact mur 2(nfangs angentelym ift!

○ Şinbin (Şirfchfulf. Spriñdjw. V, 19.), mähle mit Borficht beine Nahrung, bamit bie Fruckft bir nicfjt zum Iobe gereiche! Irinfe nicht von ber Dutelle, bie ganz Salz ift uno bich mit sujt entzündet uno je mefyr bu von ifgrem Strome trinfft, beine bürftentoe Seele bod) nicht fitillt! Şalte beine Füne von bem Baume zurihd, in beffen Zmeigen ber Too bauft! Esife zum Baume des Sebens, zu Chriftus,

1) Dieje uno bie zunächjt vorbergetyentbe Stelle fübre ich an, weil in ifnen bodi einiger Şaud von \$oefie weft. 
bem unfterblichen Riebbaber ber Sungfraufchaft! Eine freie junge $\Omega$ ulh bift bu noch; lege beinem Scalje fein Joch auf! D Perle, Iodjter bes Meers, verjente bidy nicht in bie Tiefe! Der Taucher Kat bich ja aus ber Tiefe gezogen, meil bu barin unficftbar marjt. Fochter bes Wafferb, fei

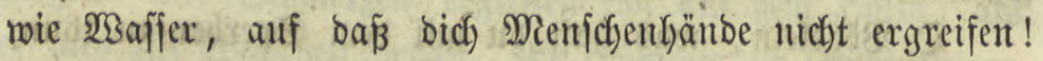
Tochter bes Feuers, gleiche bem Feuer, uno ichmiege bidh nie an ben Bufent eintes Mannes! Iochter bes Bseiftes,

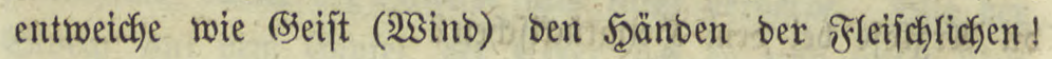

\section{An Den Erlö|er.}

Freis bir, o Rebenbiger, ber bu burch beinen Too un auferwect und erneuert hajt! Sieh, unjere 3unge fingt bir auf jebe möglidye Waeife Berlyerrlichung. WSir Yyatten zwar wobl eine Spradye, alfein burch bich habent wir jie aufs Neue gemonnen; benn anjtatt ber (Bottes(äjterungen ${ }^{1}$ ) hajt bu ifyr burch ben Tag beiner Errlojung füllle ber \&ob= preifung gegeben. Wir batten wohl auch 2tugen; burd) bich aber murben unjere \$upilfen aufgetban, weil bu uns

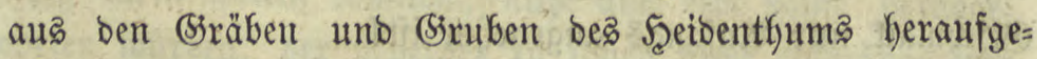

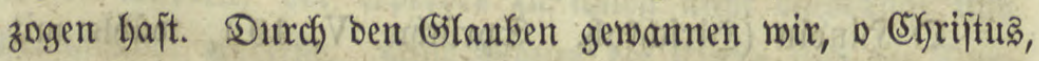
ueue Bungen; ein neues Wort hajt bu uns gelehrt uno burch) beine (Bejänge uns gereinight. Durch bid) maro

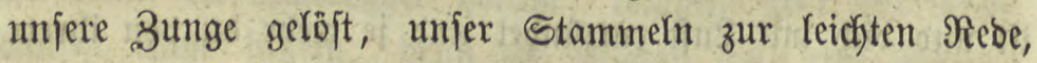
unb bufteno fteigt aus unferm sumern bie Stimme ber

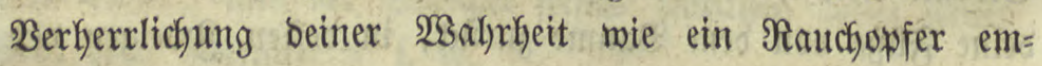
por....

Durd) neue Inftrumente, bie but gejchaffen, wirb bein

1) พюzu bie Bunge nämlid fo oft miß̧braucht wiro. 
Sieg vertünbigt, ıno bie zuvor gefägmten Zungen, bie bu gelọ̈̂t lyaft, werfünoen laut beinen (Slauben. Selbjt harte Felfent ${ }^{1}$ ) thatent beinem lebenbigen Samen, ber auf fie fiel,

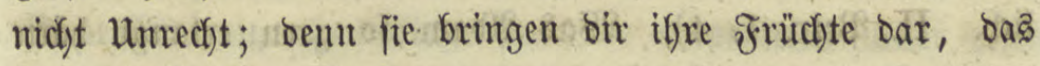
Befenntnití̧ ifyer Bungent....

Sieb), bieje Barbe von Worten hat bein lebenbig Wart gegeben, bas bu ung gejchenlt hajt; biefe Frucht trägt bir bas Fero meines Willens, bas bu bebaut bajt. Diejen Sranz, reidf an jeber Schöntheit, want bir ber Boben mei=

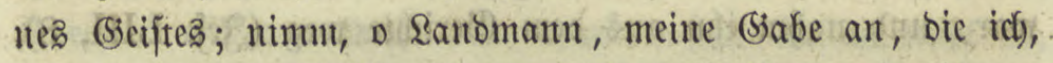
bein \&anb, als Exittingsffucht, bir barbringe!

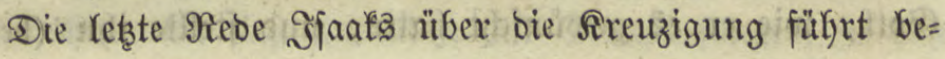

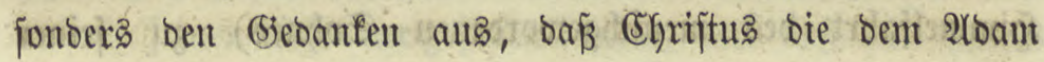
unt ber Eva gebülfrento Strafe auf fich genommen uno

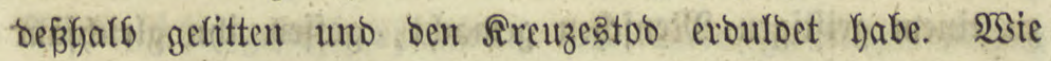
man gleich aus bem (singange fieft, ijt bieje $\Re$ ebe auf ben (6)arfreifag verfaßst:

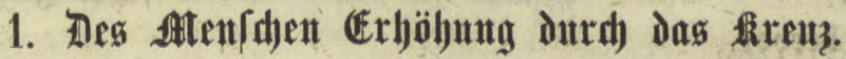

F⿻ente erfielt 2roam bie barabe, melche er verlangt Katte,

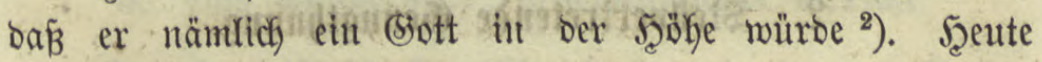
waro feine Bitte erfüllt. $23 a b$ ifym aub Bierecffigleit ver= weigert morben war, wurbe ihm ans Sinabe gemähnt; uno weil er burch) unverfchämte 2(1nmaß̧utg nicht wie Boott ge= worben war, wurbe er aub Barmberzigfeit gottähullich. Die (5ïttlicheleit, welche 2roam gewünfdyt hatte, ift beute feinen Sinbern verlieken morben, uno biefe kaben bie Siröß̄e, weldye er erbell wollte, ermorben. ...

1) verbärtete ફ̧๖erzen. \&uf. VIII, 6. 13.

2) wie bie Sd)lange ber (Eva verfprad). I. Mof. 3, 5 . 


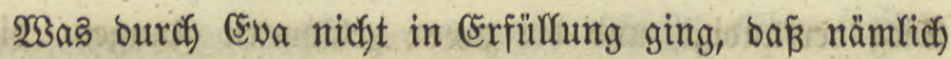
2loam wie Biott wurbe, bas warb won Seite (5ottes alls

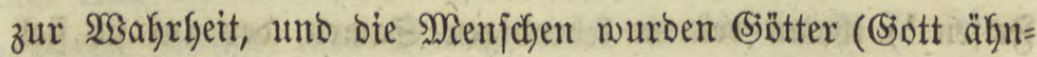
lich. II. Petr. 1, 4). Waả 2rbam fo gern erlangt bätte und weß́megen er für frech gefalten worben war, bas gab ifm (Shriftus nach feiner 2(ntunft und er wurbe, was er geliebt batte, göttlicd) ${ }^{1}$ )....

(Bott fah, baß̧ ber Menjad) (burd) seju Reiben in fei=

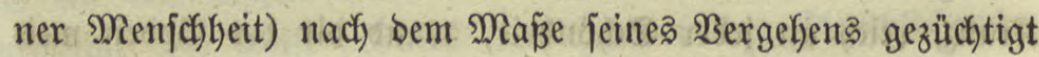
war, uno nafm ifyn aus bem (seriçte weg (Jef. LIII, 8), erhöhte ihn, nahm ifgn in ben Scimmel auf, machte ihn zu (Sott, wie er es gemünicht hatte, unb jtellte ifn (bei ber Seimmelfalyrt bes menf(chgemorbenen (Sohne s) zu feiner

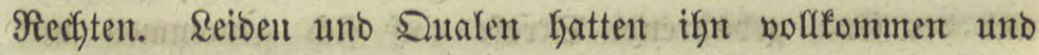
zu einem geifitigen Menjochen gemacht, goffen ifyn gleichjamr um, bilbeten ifgn zu einem netren sefectjöpfe uno vermantel= ten ify aus einem Stlaben zu eintem Şerrn. Sie trafent, peinigten, töbteten ihn, und aus bem Menfchen ging ein (Gott herwor.

\section{Stellvertretende (5emuthuma.}

2roam fünoigte unb an feiner Stelle gab fich Bott zur Bejtrafung fin. Siener hatte 20 njpeien uno Bacten= ftreiche verbient, uno ftatt feiner warb fein Schöpfer ge= fdylagen. 2roam gebülyrte Sdymady uno Iob, uno unjer

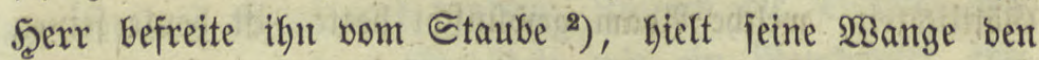
Streidjen bin, neigte jein Şaupt zu Frajtjchlägen, bot fein

1) Dabె Folgende über ben nämlichen Segenftand fommt gegen bas (Enbe biejer Rebe vor.

2) Erroarb ifgm bie felige Unjerblicffeit. 


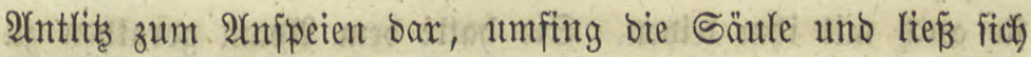
geipelıt, entzog ben Rnecht bent (Sierichte unto gab fich ferbjt ben Schlägen Preis uno rettete ifyn von affen Schulbent. Ohne Murren, ohne Rlage ftand er vermittefno unter alfen

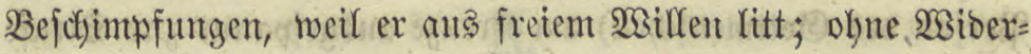

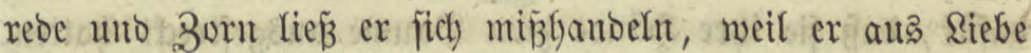
Sduntach crouldote. (5r fütgte ben ifnn Schlagenden fein Seib zu, weil er für 2rbam bie Strafe crlitt. Sein Born erkob fich gegen feite Sreuziger nicht, woil er um jeines Ruechtes willen bulbete. (5x mande fein (Sieficft nicht $a b$, als fie ifn anfpicen, weil er bas Reben (Şeil) ber Men=

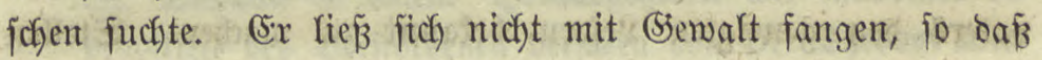

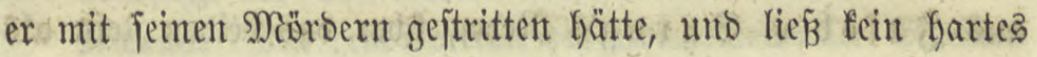

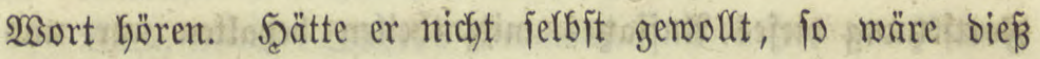

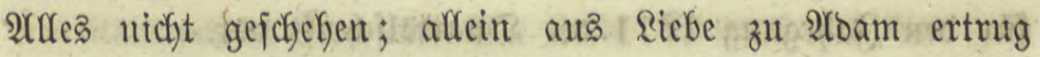

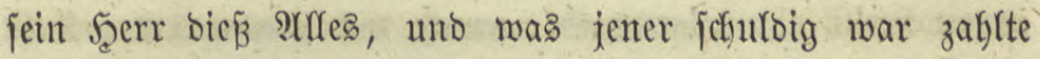

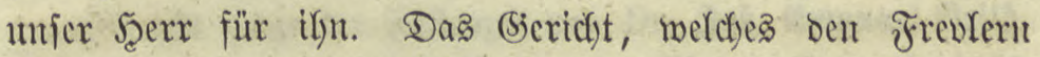
gebülyrte, fieft Efyriftus für fie aus ${ }^{1}$ ).

\section{3. đas munderbare, geheimut|juolle (beridyt.}

5 Des meisheitwollen (sserichtes, wie in ber Perjon eines Maffellojen zwei am Sireuze gejtraft murben! Durch bie Ranze maro (Eva getroffen, ourch bie Näget ifr (5atte gefdrlagen. Saseil fie bei ifym war, ba ex fünoigte, mußjte

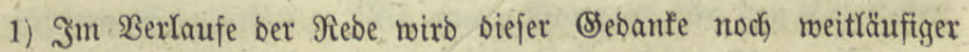

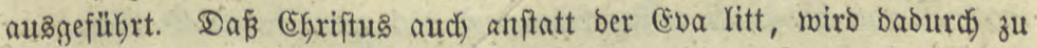
erweifen gejucht, Daß̧ (EGrifus fich bie Seite mit ber Sanze burdjftect)en

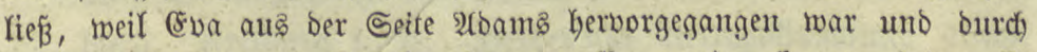
bie Bactenftreidye und (seißgefn nidjt getroffen werbin fonnte, inbem fie

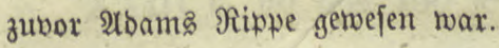

EGeol. Quartarjacrift. 1870. Şeft I. 
fie auch mit ifm leiben. Sic hatte bem 2 loam gerathen zu

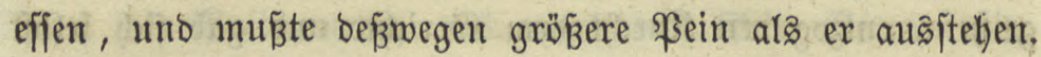
Nach bem Marßa ifrer Sünben murben fie im (Serichte be= ftraft. Die Uebeltbäter, Irbam uno (5va, waren (in ber ßerjon bes (Sottmenichen) am Rrenze ausgefpannt zur Strafe bafür, baß̧ fie ihre ફ̧änbe zum Baume auggeftrecft hatter. 2loam roaro mit Nägeln burchbofyrt, Eva mit ber \&anze burchftochen. Sie war für bas \&eiben verborgen (mie bie

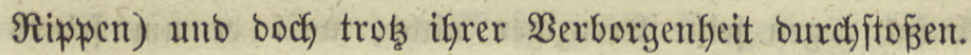

Dicje aus şjaaf gewähltèn Steffen mögen genügen, um einigermañen Sseijt uno Stil biejes frrifchen Rirchen= waters ben geneigten Scjern befannt zu madjen. Steflen

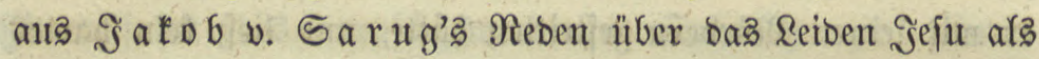
Fortję̧ung biejes 2uffaz̧es mitzutbeilen behalten mir uns für ben Jabrgang 1871 ber Duartaljchrift vor. 


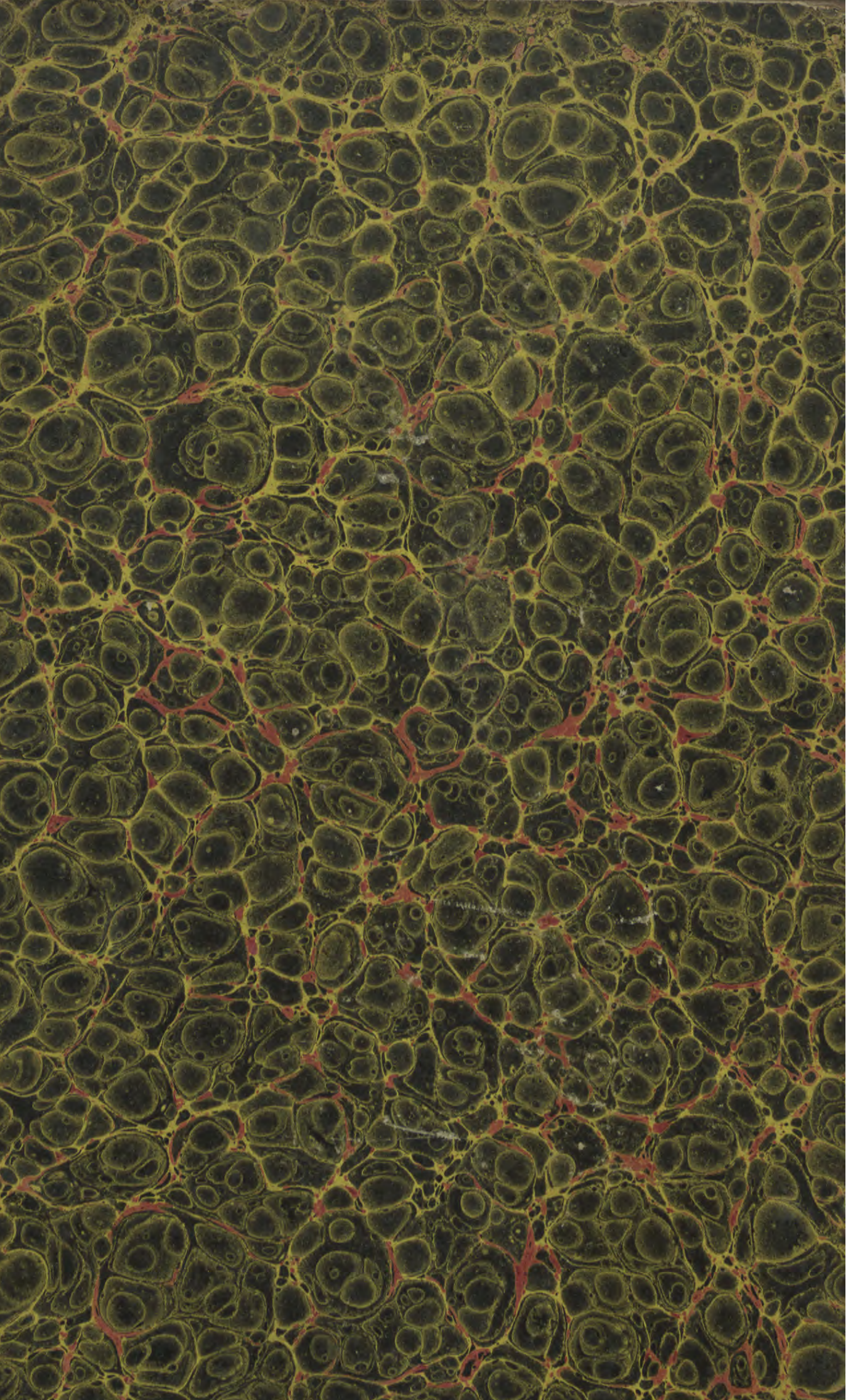




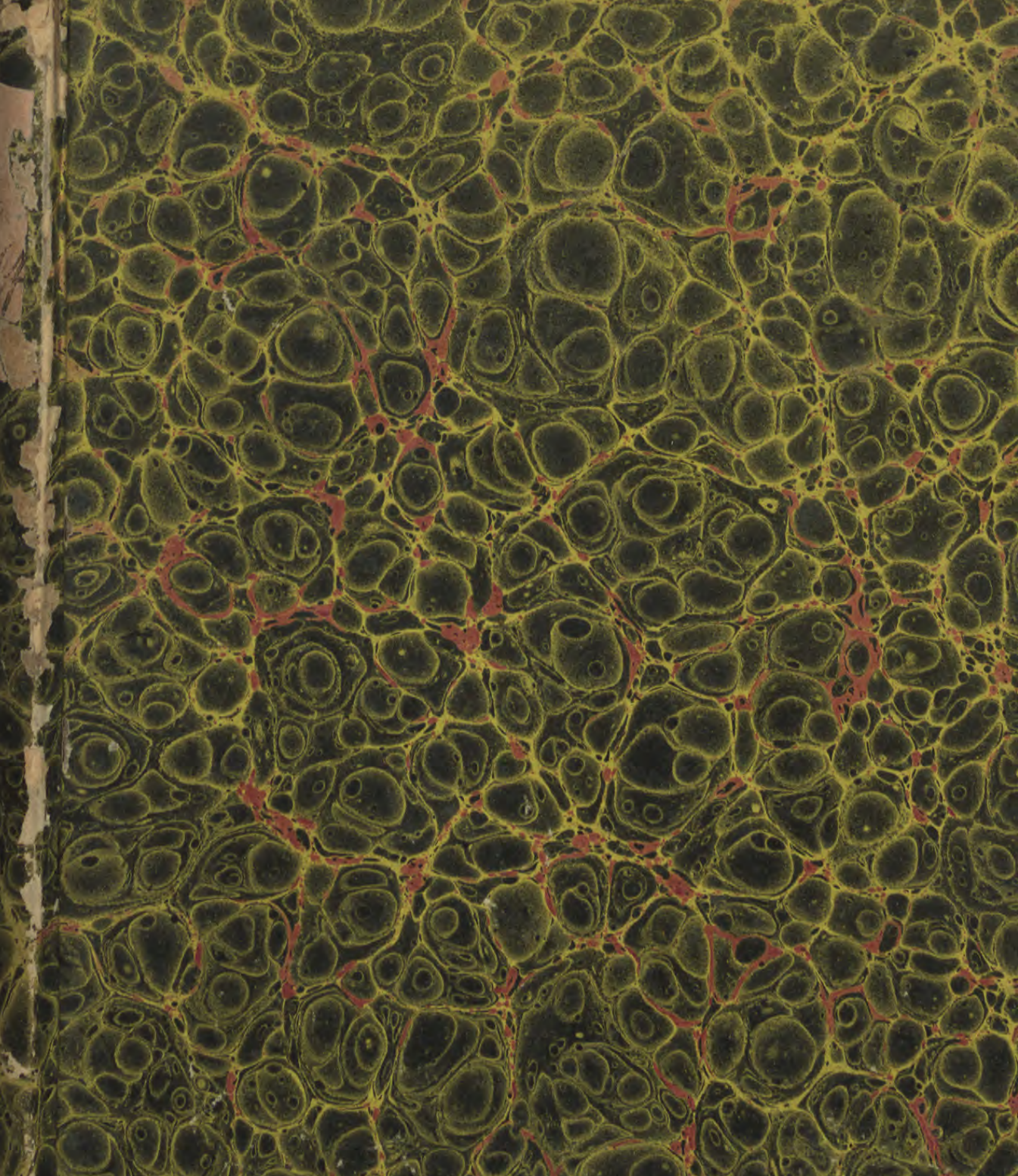

(1)

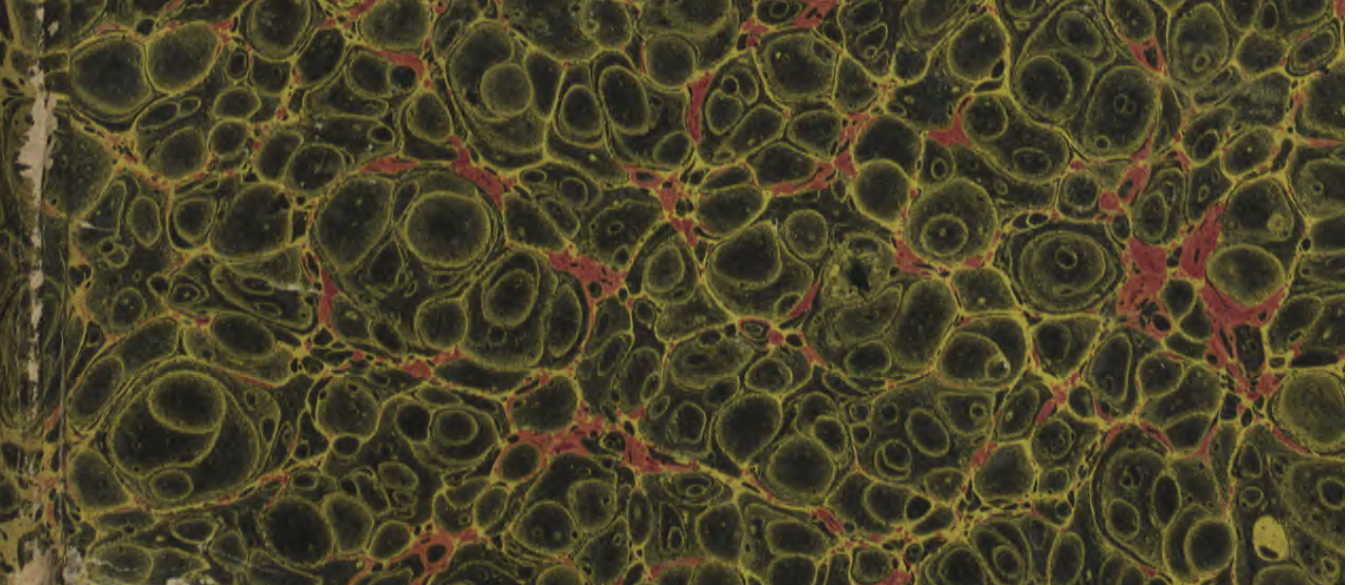




\section{(ebrologif dis \\ Suatalfdrift.}

Sn $\mathfrak{B}$ erbindung mit mefreren (selehrten

Gerausgegeben

voll

D. v. (fub) , D. Bukrigl, D. v. Adberle, D. und D. finober,

ßrofe[foren ber tatjor. Theologie an ber $\Omega$. Uniberfităt Tübingen.

\section{Dreiundfïnfzigiter Iahrgatg.}

Drittes Duartarkeft.

đ̊̆

Berlag ber 5.. \&aupp'ichen Butabandlung. 


\section{Julthaltảnerzeidhni}

Des

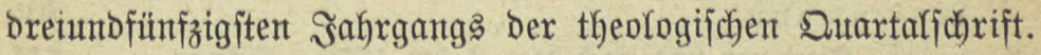

\section{Abbandluntarn.}

Die Beridte ber Evangeliften über Befangentebmutg und Berur= theilutg J̌ju. 2aberle. . . . . . . . . . . . 3

Mnterfuthungen über bie Rebre von Befes uno Freikeit. Erfter Artifel. 8 infenmann. . . . . . . . . . . . 64

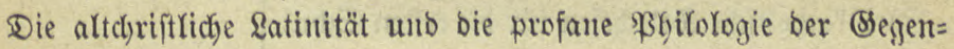

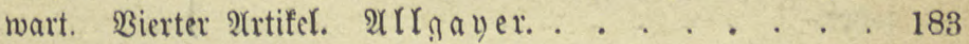

Unterjuchungen über bie Sebre von Beję und greikeit. 3meiter 2ritifel. Sinfenmann.

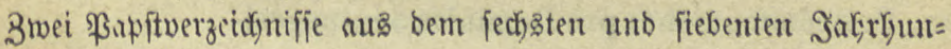
bert. $\Re \mathrm{ra} \|$ z. . . . . . . . . . . . . . . . 278

Heber ben Begriff Siturgie uno inßbofonbere liturgifdjen Sirdjent= gefang. 8 irflex. . . . . . . . . . . . . 347

Das Stebet bes 2(zarias uno ber \&obgefang ber brei Şünģlinge. wieberkolt. . . . . . . . . . . 378

Ueber unb aus গeben von zwei fyrifden Sirchenwätern über bas Seiben Jeju. Biugerle. . . . . . . . . . . . 409

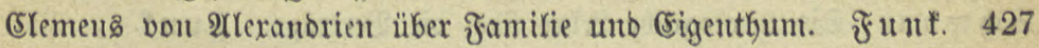
Die Malfubhynotbcife. Sd)anz. . . . . . . . . . . . 489

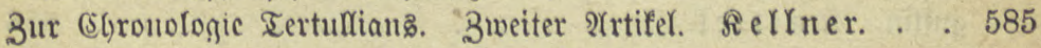
Das §ok. (Ev. V, 1 erwähnte Feft. Stawars. . . . . .610

\section{Recenfinnten.}

Thiel, Epistolæ Romanorum pontificum. Sentiş.. . 115 Dreyborff, Baḡcal. Sein Reben uno feine Rämpfe. Sinfen= $\operatorname{mann}$ 


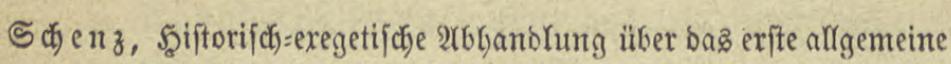
(Eoncil. Funf.

Beter sa, Die Refre bes hl. Eyprian von ber (Eintheit ber Sirche.

$\mathfrak{f} \Perp \Perp \mathfrak{f}$. . . . . . . . . . . . . . 143

Sd) äfer, Ncue Mnterfud)ungen über bas Bud (Eobereth.

Flab, 3wölf Jabre in 2lbeffinien. . ..... T\$impel 169

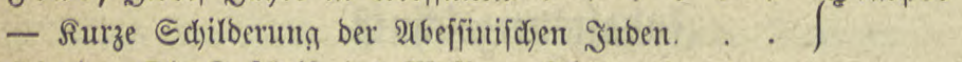

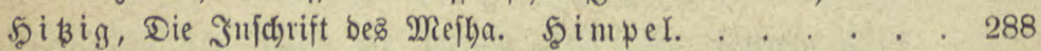

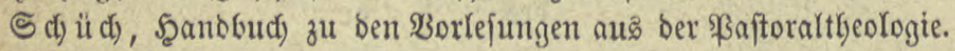

sinfenmann. . . . . . . . . . . . . . . . 305

Michelis, Rant vor uno nach bem gabre 1770. Storz. 314

Bellex, Ias Bejangbud ber Diöceje Rottenburg. Birfler. 319

Bä $x$, Bwei alte Thorarollen aus 2 rabien uno $\mathfrak{B}$ aläftina. Ş i mpel. 338

\&ütolf, Die SITubenşboten ber Schweiz vor St. Sallus. Funt. 341

Brobft, Siturgie ber brei erften d)riftl. Gabrhunberte. \&infen m. 450

$\Re$ rombhol $z$ Faftentprebigten.

Brifa a r, Die fatholificjen Ranzeliebner Dentichlanoz

jeit ben Yeßzten brei Jabrbunberten. . . . Sinjenm. 464

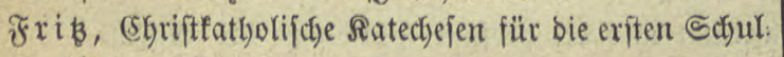

jabre.

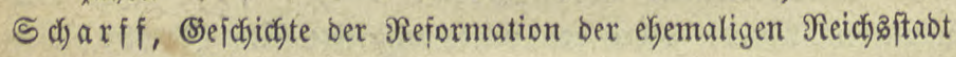

Şăly. Maier. .............. 471

Hof e r, Postcommuniones pro Dominica Septuagesi-

mæ.

Hasler, Missa secunda.

Pavona, Missa quatuor vocibus.

Berter. 475

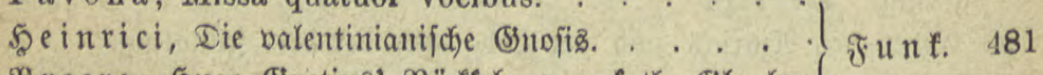

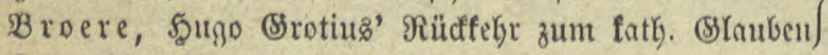

S d) mib, Ser d)riftlidje 2Altar uno fein Sdjmud. Sinfenmann. 626

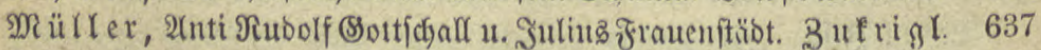

Sd) wa ne, Die theulogifdhe Schre über bie Berträge. Fun t. . 649

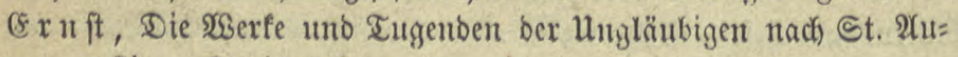

guftin. $\Omega$ nittel. . . . . . . . . . 656

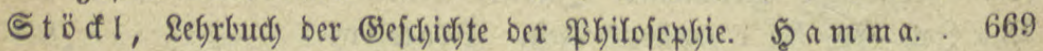

StraußB, Die ebangelijdye Eceljorge bei bem Rriegsheer.

(5) в̈ е . . . . . . . . . . . 681

Bujd)rift an bie Rebaction aus (sinfiebeln. . . , . . . . 690

\section{Piterarildore Anzeiger.}

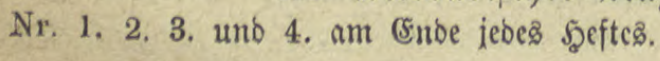


3.

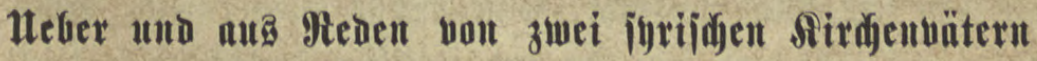 ïluer ถุด Reiben seju.}

Bon P. Pints Singerle in Meran.

\section{II.}

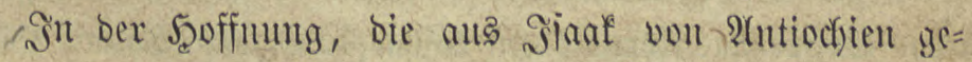
wählten Stellen, weldge ich int vorigen Jabrizange mitgetbeilt babe, dürftent belt geneigten Refern nicht unvillfonmen ge=

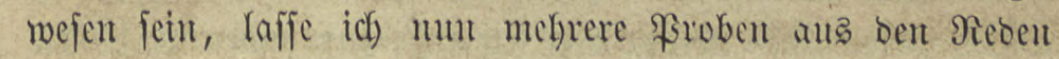

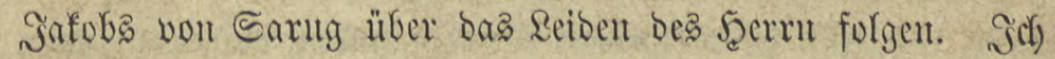
mäble babei foldbe, bie mix zu ben fabönften ber bezeicfyneten

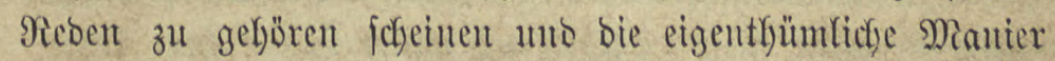

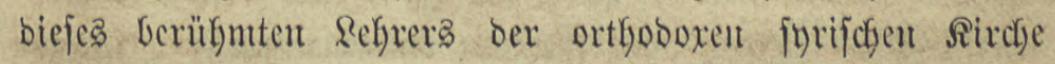
cfarafterifiten.

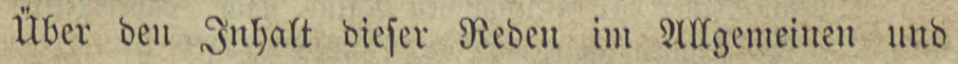
bie Darjtelfungeneife Satobs habe idy Seite $93-95$ im erjten Duartalfeft 1870 gefprodgen milo glaube bafjer, $10=$ gleich baran geken zu bürfen, ben genteigten Sejern ber

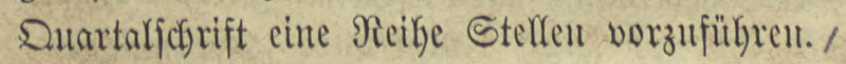

Egeor. Quartalidrift. 1871. Seft III. 


\section{Alts der erften Rede.}

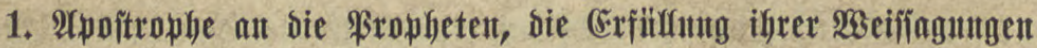

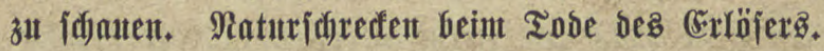

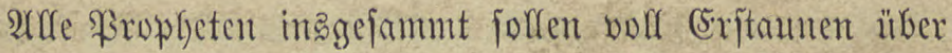
igre Dffenbarnugen, bie fie bejungen haben, herbeifommen. Romm', D Şaias, uno jiel) bas Samm ${ }^{1}$ ) ber (Sottbeit ge= opfert und getöbtet und an bas \$corz gefängt und mit $\mathfrak{B}$ hut ïberromen! SGölfe baben es angefallen, freventlich ermorbet

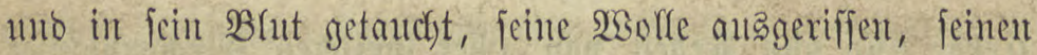
seib zerffeifdst uno fein (Sienano zerriffen. Bacharias, blick' auf uno feyau in feinen Şänden alle $\mathfrak{W}$ sunden! ${ }^{2}$ ) Seine Frentroe waren gegen ifn treulos, füfrten ifnt weg anto Durchbolbrten feine Şände. Davio, fein Bater ${ }^{3}$ ), fomm' uno betracht' ifnn auf (Solgatga! Sie burchnagelten uno

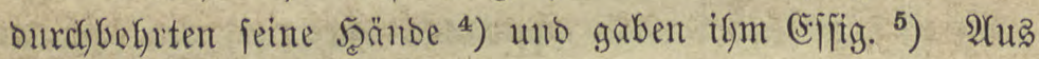
ibren Gerben Trauben batten fie Bafle ${ }^{6}$ ) geprebt uno gaben bom Sofnte dic Frucht fu foften, bie ber Baum Sionz hervorgebract.t. Das \&amm bes Sebells ${ }^{7}$ ) fiel in bie Şänbe möroerijcher Wälfe, bie burch iljre Biffe feinen Seib graujam zerfleifutent. Das Sireuz bereiteten fie für feinen Seib, die Sanze für feine Seite, Dornen für fein Şaupt, Nägel für feinte Seänoe, Mik̄hanblung für feinten Rörper. Die Schöpfung ge=

1) Şฺ̆. LIII, 7.

2) Bactar. XIII, 6.

3) Stammbater ber men[fflicfent Natur nach, bafjer Sefus aud) Sokn Davibs genant wurbe. Suc. XX, 41.

4) SHarm XXI, 17.

5) $\mathfrak{P}[a$ Im LXVIII, 22.

6) Ebendaf. - Bergleidje V. Mof. XXXII, 32.

7) Sefus, das \&amm Sottes uno bas \&eber. Soh. X, 10 unb XIV, 6. 


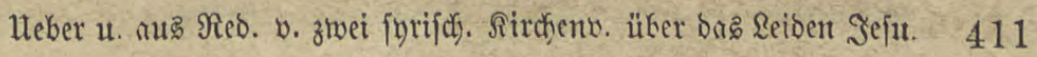
rieth bei ber Ermoroung bes Solytes in Unrube, erbebte

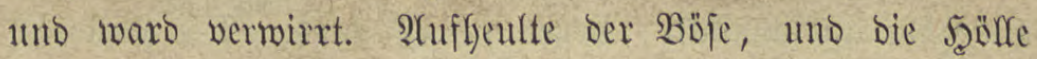
exjefauberte, und ber Iod ward vernicftet. Die Sucfiten (bes Seimutela) murben verfuitert, bic Strablen verbargen fich, bie Schöpfung ward crichüttert. Die (vom Siböpfer burch Naturgefese) gebunbentu Naturen exlitten eine ver=

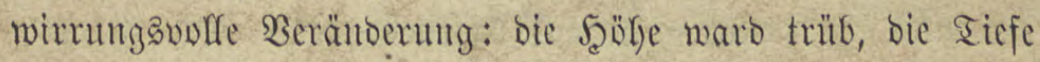
trauerte, die suft murbe bunfer, sas sicht cntichwand, Fin=

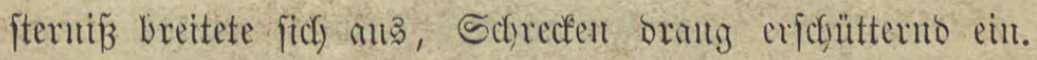
Die Sonte war entflolnn, ber Mionto verborgen, bas Fir= mament verdunfelt; Sammer ward erregt, fibmerzlickes Reid = mejen entitano, Sntjeben berxidyte mit Mircht.।

\section{Der Gefteuzigte (5ott แuto Menid) zugleid).}

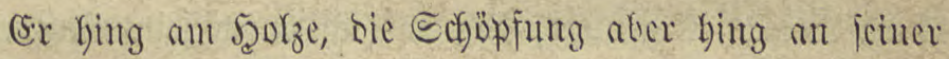
unfidytbaren Macfyt. (5x war nadet gelaffen uno wob ben sifien cin (Simand. (sffig trant berjenige, wetefer ourch)

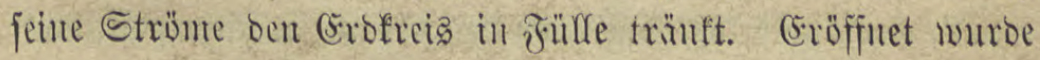
die Seite beffen, ber bem Mrofes ben Meg burch's Meer bafunte. Sine Dornentrone jeşte man jentem anf, ser bas Sicft zur Somne geftaltete. Selbit ben Engeln unerfaß̧bar,

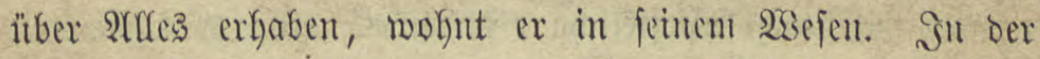

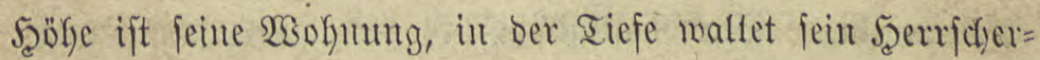
mint, uno - er fängt an Şolze! Sein Âleio ift glüfeno Fenter, Flammenbrand untgiebt ifn, feurige Reigen bienen ifym, uno er ift verachtet am Sirenze. Ungeben von (Silut,

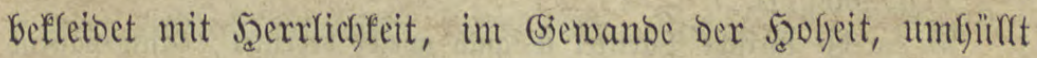

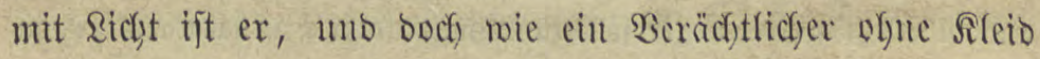

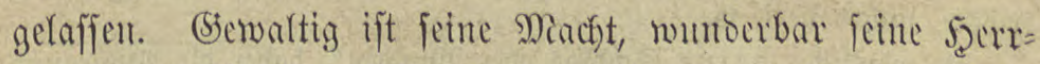

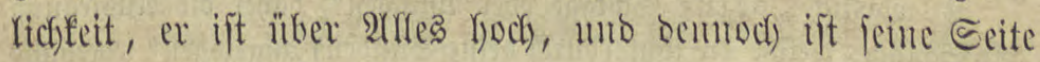
fdjonungslos aufgeriffen. Şgu, ber afle Erenturen foruf, 
burchjtacken fie mit einer Sanze, und ben Scöbjftweifen, ber

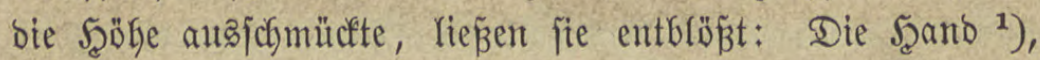

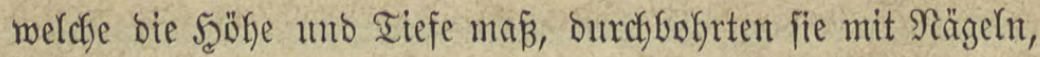

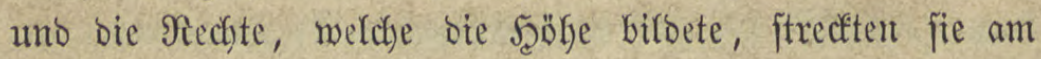
Scolze aus. Dem Mambe, ber bem roam ben (Sieift ein= Gauchte ${ }^{2}$ ), reichten fie (5ifig; bas 5̧aupt, welches bas \$ุaupt des arus iit, bebectent fie mit Dornelt./

\section{Aus der z̧weiten Redr.}

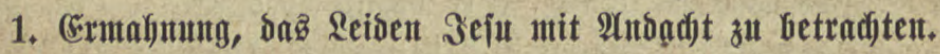

S) Seerbe! Sieh, über bas Seiben beines Seerrn wirb geiprocken. Şöre nicht mit (sirübelei zu, fonbern mit Siebe, uno exfreue oich! Dev gute Şirt jeb̧t fein seben für feine Schafe ein; es genügt, bấ er bicf burch fein şut exlöst fat, gegrübelt folf barüber nicht merbent. (Ex ftand vor (S)eridyt, trane um beiner (shre wilfen Scyntach; es folf mu! ${ }^{3}$ ) ber bich erlöst hat, vou ben (Sirüblern nicft befcrjimpft werben. Die Sünger floben, er aber hielt aus, bie Seiben

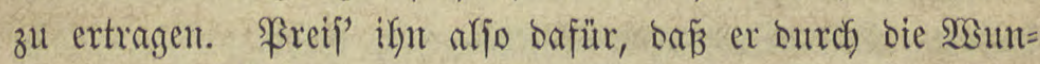
bent für bidf ${ }^{4}$ ) dir bie Freikeit gegeben hat! Das Reiben, welches bie ganze Ilpoftelfchaar verwirrte, trug ex alfein mit geloenmiltbiger Stanbbaftigfeit.)

1) Die flactje, bie Spanme. Sfai. XL, 12.

2) I. Mof. II, 7.

3) Ia bie fyrifde Partifel d' anth we il bebentet, fant paffenb audi) überfebt werben: "er foll mun, weil (ober ba für $b a \tilde{\beta}$ ) er bidf) exlöste, nidft" น. โ. w.

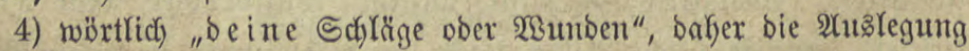
"bie Schlöge, weldhe bu ifm (burd) beinte Sïnben) zugezogen" ebenfalls zuläifitig ift. 


\section{Seelenfampf ber Sünger bei bem Reiben beß serrn.}

Daß (Serücht ber (brofjentoen) Ermorbung fam fodnelf

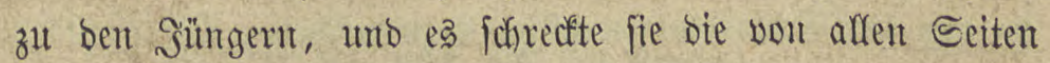
auftaudfenbe Furcfit. Siebreich waren jie an ben wafbren Enfn (bottes, ifjren Mieifter, gefeffelt unb murben baker, ala fie bent (ifm brokenton) Ioo fafen, getwaltig won

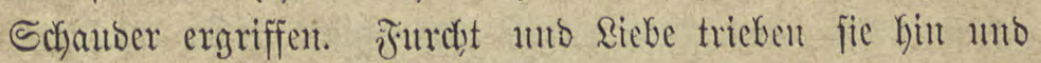

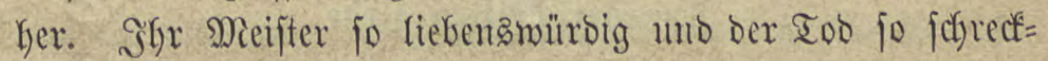
rich! Waie wito es mut werben? Die furdst vor bem

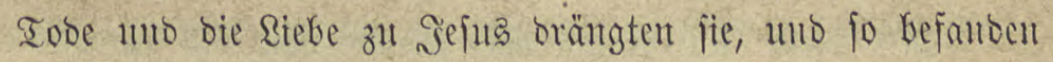

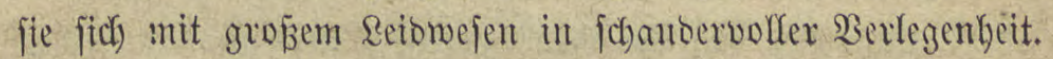
Die Riebe zum Solgne bielt fie nänlicly fejt, von ifm nicdyt zu Yaffen, bie Fantedt wor dem 'oube hingegen trieb fie an wegzugehent. Shre siebe war mit ber Riebe (Efrifti inutigit verwebt, um bei ifm alszzllyalten umb bic (Biefchichte ber (brokenben) Ermoroung beffelben erfüllte fie mit groß̈em Sdfrecten. Dab Edfmert war erboben, um fie ilt eiliger Berwirrung fliefyen zu madfen; bie siebe aber wollte fie mit Buverficft zurieflyaten. Der Tob erregte Edfauber Yjinter ifynen, zur Entfermung fie anzutreiben; alfein riebents= würoig ftand ber (Eritgeborme ${ }^{1}$ ) bor ifnen, zum 2(ushalten fie zu berwegen. Bor ifnen walfte bas Meer ber Riebe bes Solfnes Ssottes, alfein hinter ifuten brobten bie Priefter gleich) ben 2(egryptern. ${ }^{2}$ ) Jeier bie Riebe, Dort ber Tob; wem follten fie bent Sieg gebent? Fürchterlich war ber Tob, lieblick bie siebe beiberfeits. Die Riebe, moburdf fie

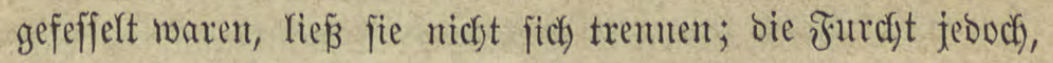

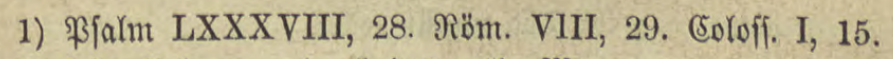

2) beim Hebergang burd bas rotbe Meer. 
in bie fie verjunfen waren, erfaubte ifnen nicht, zu bleibent. פäbreno fie bereit waren, aus siebe zum Sobne ben Tob

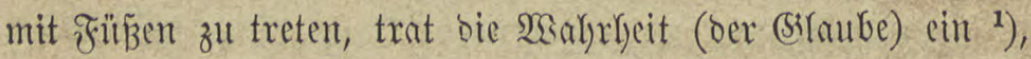
fie von ber Ermoroung wegffieben zu machen. So befanton fie fict) znifdsent Furdyt und Riebe in Berlegentgeit, wo unto

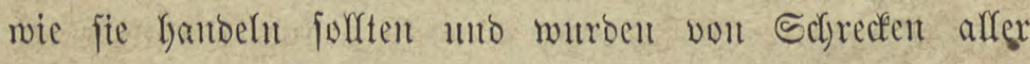
möglicken Borjtelfungen verfolgt./

\section{Auts der dritten Rede.}

\section{Bon ber Riebe, mit ber mat von Seju Reiben fpredjent folf.}

Mit Riebe un faut ber Maub von bir iprecten; bellit aud) bick) lont bie siebe gezogen für une zu leibent. Das größste Beichen der Riebe bes Saters ift ber Iod feines

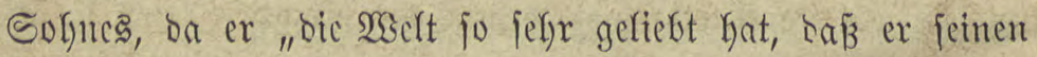
eingebornen Sofnll bafingab." (รol). III, 16.) S wie fel)r bat ex uns geliebt, baßj er feinten Soln dem Tobe preisgab

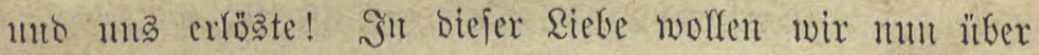
ullfern Erröjer rebent. Siroje siebe übt, wo fie immer ift, (semalt, uno es ijt bei benen, bie fie bejiben, feine mächtigere Rraft. Was fonnte wohl ben Sater benegen feinen Gobn linzugeben, als die siebe, bie ba größer als 2rmes ift, wie gefchrieben fteft (I. Aoriuth. 13, 13). 2(uf biefe 23eife ${ }^{2}$ ) naket ber Menich ficf) (Bott, weil autd) ex fo fich uns nabte uno siuter nus uns geworben ift. SBer fam wohl ben Bater lieben, wie er geliebt lyat, noer wer vermag ben Eofn

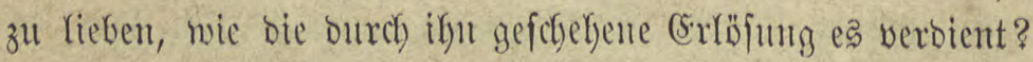
SSer ging mit ifym zum (Sierichte anto erouldete Sciben? Dic Siebe affein begleitete ifn afs er Demütfigungen erlitt.

1) Belebreno, baß́ ify Tod unnüb wäre.

2) nämlid) butch bie giebe. 
Da bie Rrenziger woll töbtlichen (strimmes wiber ifyn gerï=

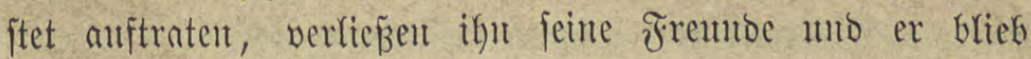
alfeit mit feiner groß̧et sicbe./

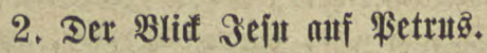

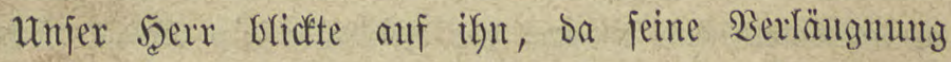

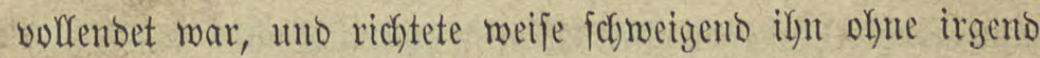
ein WGort. Der Bride bes Saerrn war voll Eimt uno WSeiaheit uno zeigte ftilf wie burch WBorte bem Şaupte ber Sünger jeine Strafwüroigfeit. Sr bliçte auf Simon uno fprach gleichfam zu ifym: "WGarum, o Eintun, verläugntejt bu mid) zur Beit bes Rcisens? S Freunto, wo ijt wohl bie beiner 2rpoftelwürbe geziemente Riebe? Scaupt ber 2(poftel, warum fliefjit bu zur Beit bes Rampfes? Da id) euch) affe jegnete, warjt but ber (Erjte, uno ba ich Ifrone verfprach (Matth. XIX, 28), ftantoft dil audf an ber Spize. Du floheft von mir nidst, anker heut, o süntger! Im Rampfe verliepejt ou mich; wie liebjt bu mich aljo? 23ann, o Eimon, lyaft bu mid) nicht gefaumt, außer Yeute? WSo baft bu mich vergeffen als hier, ba idf vergöbnt werbe?

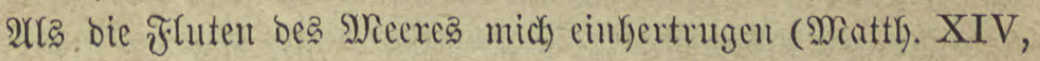
25-28), tieffit bu zu mir; warum verläugnejt bu mun, ba

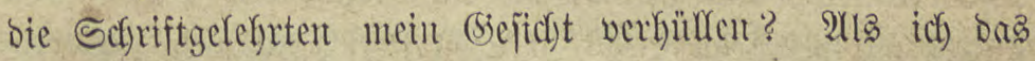
Waffer in Wein vermanbelte, warft bu nare; jebt aber, ba bie Priefter mich anfpieen, bleibjt bu entfernt. Da idf in ber 2Büjte bas Brot wermef)rte, gabjt bu 2(ufträge ${ }^{1}$ ), uno nun, ba bas Bolf (balle fereitet bat, milffit but mich nie

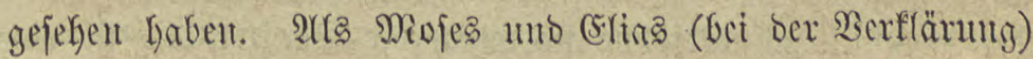
auf bem Berge waren, haft bu micl) nicht vericfmälyt; Kier

1) Geim গ1tatbeilen ber Brote. 
aber, weil mich Edjmach ummringt, verläugnejt bu mich. Nichtig ift beine Siebe, wemu bu mit ben Beiten bich änberit; benn wer mafrbaft liebt, dent wantelt auch cine Prüfuntg nicjt um. Ein wabrer Freunb ber siebe erweist feine siebe zur Zeit Des Rampfes; warum verläıgnejt du jebst micl),

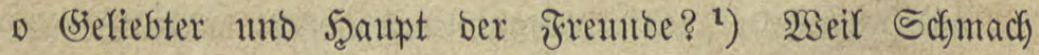
uno Epott mich getroffen, femnit bu mich nicht metr; uno wegent ber Reibent, bie mich umringen, haft but mich ver= \{chmäht. Som Frieben bift bu mir angehangen; weil aber Arieg entiftanoen ift, hajt bu mich verlaffent uno verlänguef́t mide), als fenuteft but miç) gar nicfst. Beitumitänoe botent bir Seranlaffung, midú zu verläıguten; cine Siebe jebod),

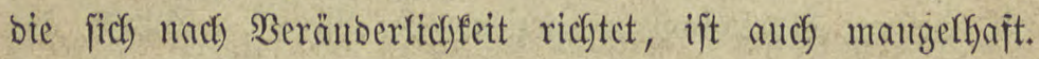

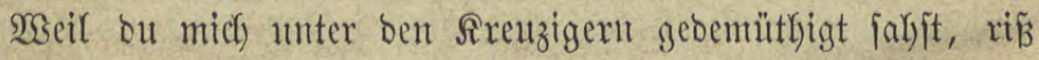

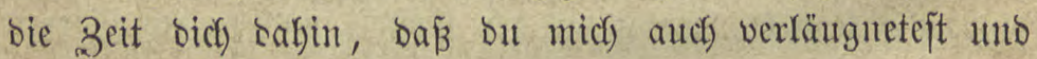
won mir weggiengit."

Diể beutete des Sofntes Schweigen bem Simon an.,

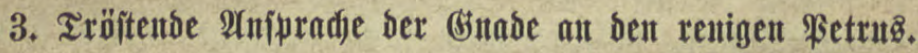

Nacfjoem bie Betrübníz fo auf ifn cingebrungen war Inlo ifn von alfen Seiten übermältigt hatte, fam bie Bnabe unb breitete iffe gittige über feine Eeelenangit nus. Romm, - Simon, unto bringe Thränen der Buß̌e bar, bie bir noth= wenbig fino! Wseine utatbgeferst! Wseinen geziemt fich

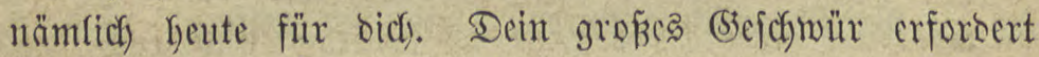
viefe Thränen; benn ein foldjes Seiden wiro nur butch)

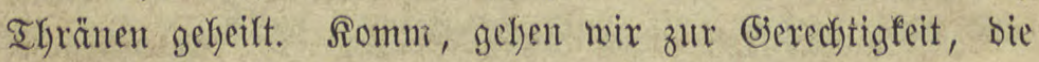
bir brobt! Sadh verföbne fie butch bie Eellfzer, bie fie von uns hört. Nimm Ifränen mit bir unto bringe biefelben,

1) b. i. ber Axpofter. Soh. XIV, 14. 15. 


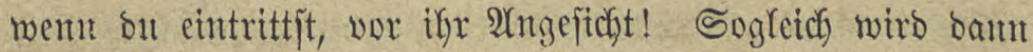
bie ganze Bjhut ifyrer Erbitterung auffören. Bring als Rauchopfer Shränen bar unto zünde amftatt Specereien

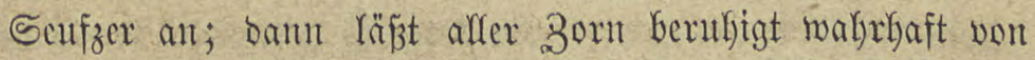
bir ab. Das Fener ber Sïnbe wiro Iur burch SBeinen gelöjcht; fchütte aljo Ifyränen auf ben bir brofenton Branto! Eieff zu, baja bu bich ja nicht ber Serzmeiffung ergibft; fonft ift es bein Iob. Faffe Bertrauten uno flef' um (Ex= barmen, unt bu wirjt nufgenummen.",

\section{Aus der fiinften Kede. ${ }^{1}$ )}

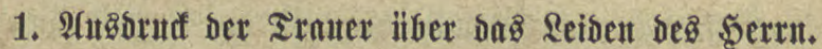

(joroß ift ber Sammer für jenen, ber mit Heberlegung betrachtet, wie ber Unfdrulbige von ben Echulbigen an's

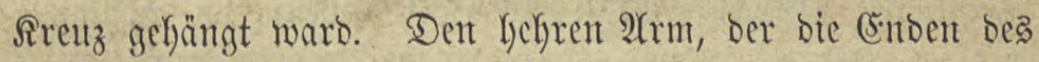

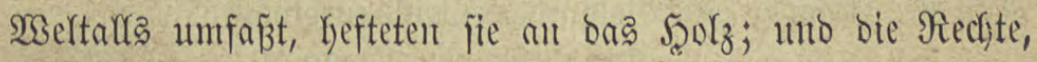
welche bie Şöhen auboblynte (รef. 48, 13), burchboryten fie mit Nägetı. Dem Muntbe, ber bem Rroam ben Beift ein=

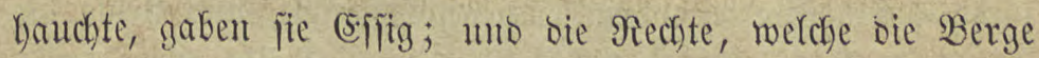
mog (Šef. 40, 12), bingen fie aut Nägetı auf. Sie er=

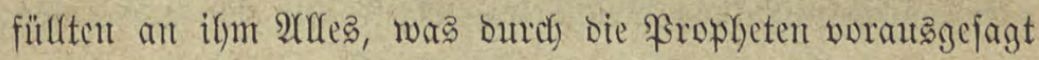

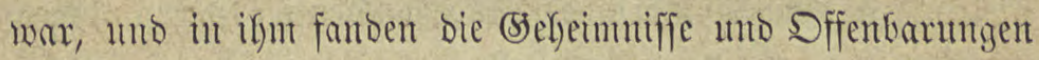
Der Bserechten ifre Beftätigung. Sie mifchten ifym Effitg unto reichten ifm (Silfe wie gefagt ift (Fjafm 68,22). Sie

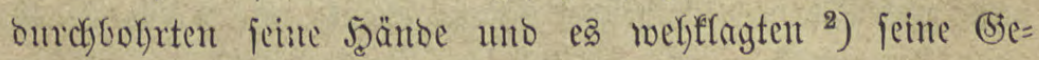
beine, wie gefchrieben ftegt. Stürmifech verlangten fie feinent Iob, brangen tobent auf fein (sicrickt, ba er bod) gantz

1) Die vierte $\Re$ ebe enthält faft mir prophetiịche Stellen beả alt. B. utb ben Nadfweis ifrer Erfüllunty an bem Erröfer.

2) Bfalm XXI, $17 \mathrm{ff}$. Der 2(uborud weljflagen ift in ber fyrifd)en Heberję̧ung. 
fofurblos mar. Sie theilten feinte Rleiber uno verböbntent ifyn, objchont fein Bergegen an igm fith fanto. Dffen ftanto ber Şimmel uno bie Engetreifen ftanden verftummit u. f. w./

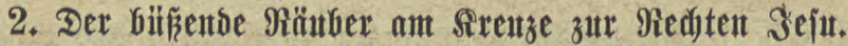

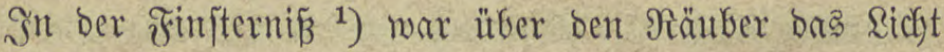

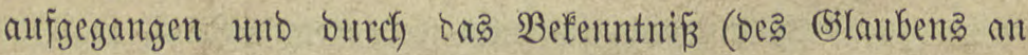
Sefus) wanb und verichaffte er fitf bie Rrone bes Robes. wsähreno ber büftre Dampf ber groß̧en Rucblofigfeit über: mächtigt gemorben war, rief er zlt Egrifttıs: "Sebente

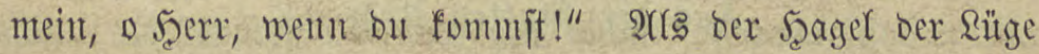
von ben Siruzigern Kerabraffelte, entbrannte helf bie Reuchte

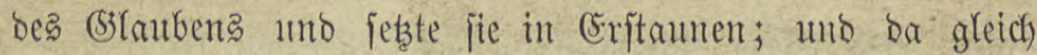

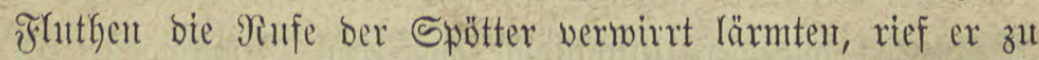
SGriftus: "Siebenfe mein, o Seerr, went bu fummit!" 2tra ber Erröjer auf (Biolgatha allein entbröat bahing, uno weber Segionen (vont Engelit) nod) ber Waagen (ber Efyerll=

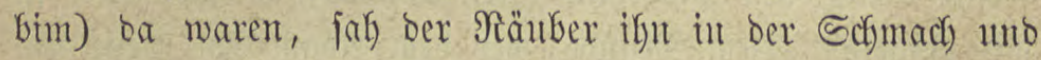
nicfyt in ber (Silorie, worin er herrfich ftrafilt, uno frebte ifin

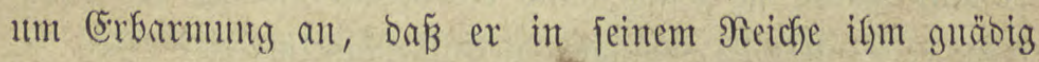

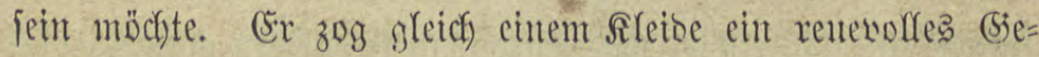
bet an, es ifym barzubringen, indem Senfzer feinen sippent cutquollen: "D Pforte bes Rebens, lá̉ mich in bent fojönten Sot eintreten! Sebentiges Brot, gib mir an beinem Iifche

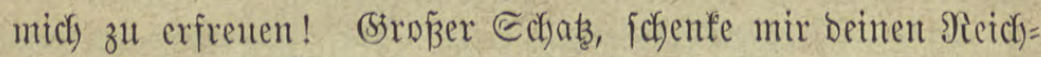

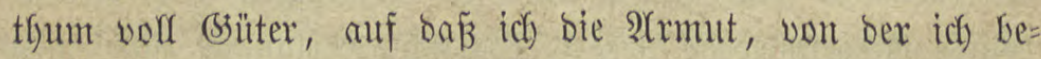

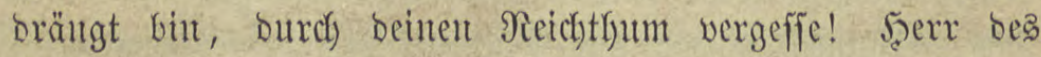
WSeinberges, ber mit ben 2 trbeitern am Norgen um einen Dentar (Miatth: XX, 2) übereingefommten, jtelle midd) ifnen

1) bie beim Tobe bes Şeilantbes entftant. 
gleid), objchon idy) erit unt bie eiffte Stunte in beinen 2 Sein= berg eingetreten bin! Wser gut fich angeîtrengt hat, erfältt

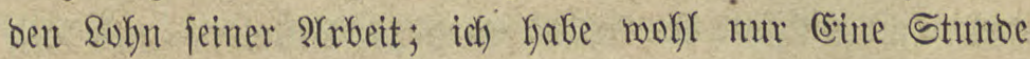
bes Tages gearbeitet, git mir aber boch it beiner (Erbarmung bas Reben! Dic bom Morgen an gearbeitet, forbern bent

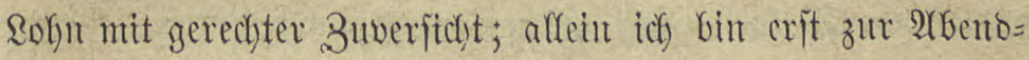
zeit getonmmen, erbarme bich sentued) ḧber mid) Berfornen!

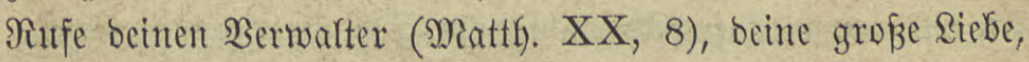
mir ben Rofyn zul geben! Mich rufe zuerit, bamit burdf mich bie erften 2frbeiter ermuttyigt werben! Eine Stunto lang lyab' idf) bei bir, o Rönig (Shriftus, gearbeitet; rufe mich) zuerft, auf bá̧ $i c h$ felig werbe uno burch mich bie (5itgefinten erfreut werben" ". f. f.,

\section{3ejut 2 futtwort barauf.}

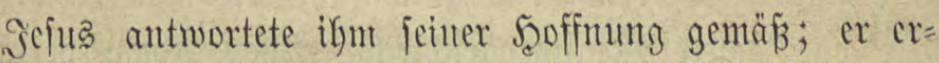

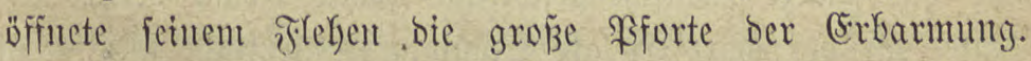

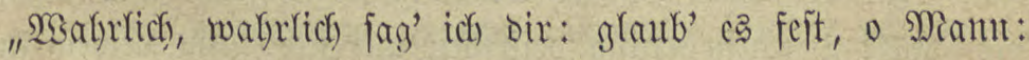

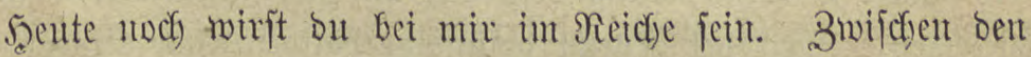

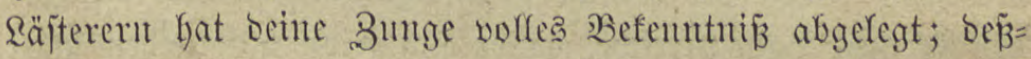

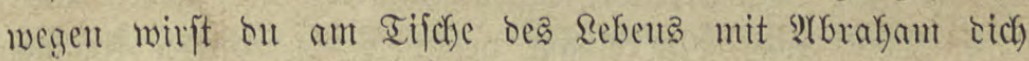

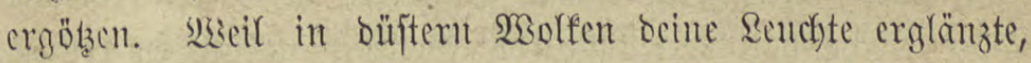
wirit ou in Brautgemact)e bes Rebens mit Dell Scimmelabe=

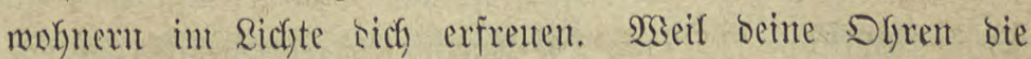
tobenten Etimment ber Räfterer gebört Kaben, tröfte ich bich

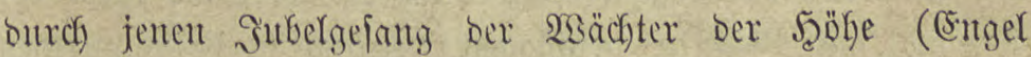

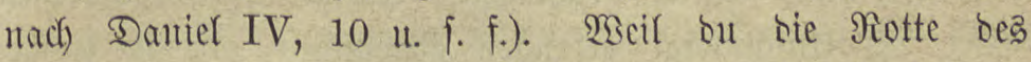
Saiphas uno ber unfaubern srtefter veradstet hajt, beffeibe idf) bicf) mit bem (sicnsande bes Ricftes im Brautgemadfe bes Richtes. Sich gebe bir bon Echlüffer bes Richtes; ziely in (5ben eill uno bereite ben $\mathfrak{B e g}$ bem Rönige bes Richtes, 
melchen bas Bolfe wermorfen fat! Reit' auf Fener babin unb wanble auf flammentom SGege! Edyreite fafuell bafin uno begib bich zil ben Echaaren ber f̧immlifchen! Bereite

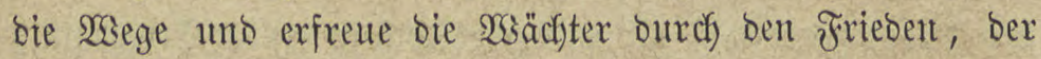

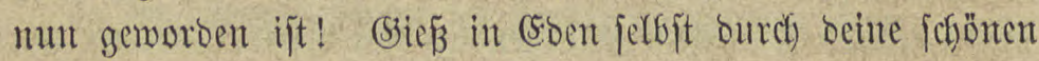
Worte ben frieben aus! Cage ben Bäumen bort: "R̂Abam ber Evbe fefrt zurüct!" Wenn bir feurige Schaaren ent= gegentommen, lẩ bich nicht vont Échauber ergreifen!"/

\section{Ang der feddstent Rede.}

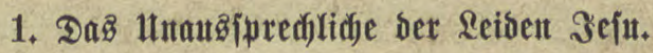

Wex ift im Stande, bie (Sierichte ${ }^{1}$ ) des Sohnes alls= zuprecten, und weldser Munb vermag feine Seiben, wie fie maren, barzuftellen? Die Sajt ber Welt trug ber Seld

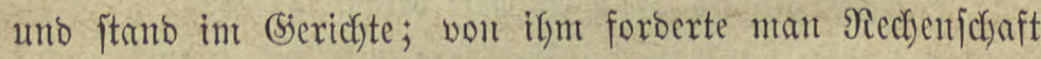
für bas ganze Menfchengefd)lectyt. Was 2(bam verbroctsen l)atte, barüber marb E.r als Schulbiger unterjucht und nafm bie ganze Bersutwortung beffelben auf fich, ım Seiben zut ertragen. Weil bex Rnecht gefünbigt Latte, befam ber Şerr ber freibeit Bactenjtreiche, ba er fict) felbft fingegeben batte, baß̄ 2rlles, was ben 2roam gebührte, über ign fommen pollte. Eva batte verlangt, bie Sottheit an fich zu reipen;

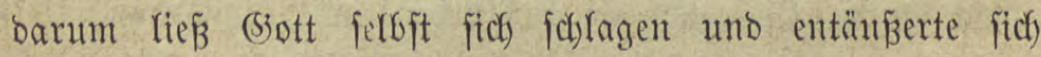

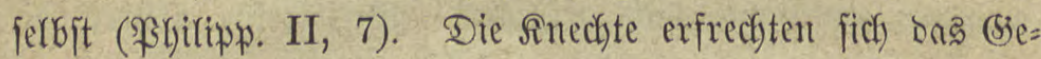
bot zu verachten; Deß̧halb murbe anftatt ifgrer ber Seerr ber Snechte mit (Sicibeln gejchlagen. 2tnjtatt der Echulbigen wato ber Unjchulbige gefangen genommen, um fie zut be=

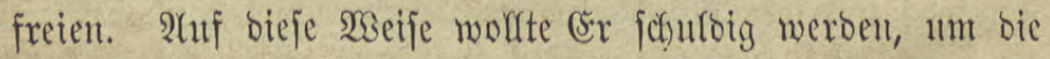
Schuldigen zu reinigen.

1) b. i. bie über ifn ergangenen graufamen Urtbeile. 


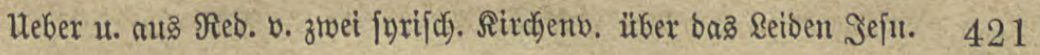

Blicté auf feinte frrone, unto zäble ifjre tiefen Stiche, menn du fannft! \$ुb̈re bas Siericht über ifn uno berechne feire Reiben, menn but es vermagft! Du bift nicht einmal im Stande bie Bafil ber Dornen zu exfaffen, uno jo fannft bu altch, wenn bu es recfyt ermägit, in bie Berectumutg Feinter seiben bich) nicht einlaffen. Das (siekeimniäs feiner Seiben ift in feiner frone abgebildot und auf fein Scaupt gefetst; gleicf) ben Stackeln bicht waren bie Reiben, bie er auf ficf) genommen. (Sileich) ben Stictent feiner frone war audf bie Reihe feiner Schläge, nub fein (Sseriçst war mit Reiben fo bicft bejegt, wic feine frone mit Dornen.,

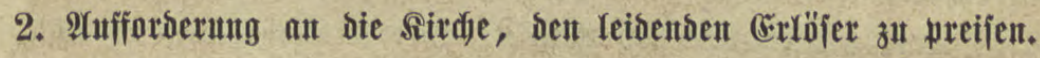

Sing' ifym Rob, o Rirche! Deinetwegen litt ex ia Sctumach und Setoen uno Schmerzen uno ben Iob am

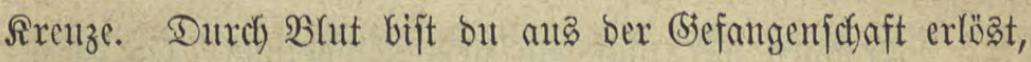
- Braut bes Röniga! (Extöste, preif ifu! Durdf) fein Reibent fat er bich) frei gemacht. (Ermache lyeut ${ }^{1}$ ) mit beinen

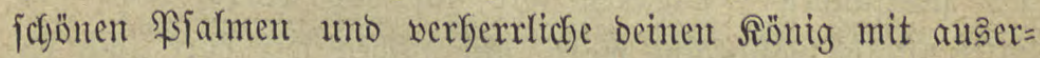
Yejnen Biefängen! Um beiner G.hre willen warb er von Nieberträcftigen befchimpft. Esyre ifn, preife, bante, juble, berferrliche ifnn burch Pfalmgejang! Sn biejer Nacft ${ }^{2}$ ) ftand or beintetwegen wor (sericht; wacke ifm zu (5.hren mit Siebe; benn aus siebe zu bir bat ex fich mib̈landeln laffen.

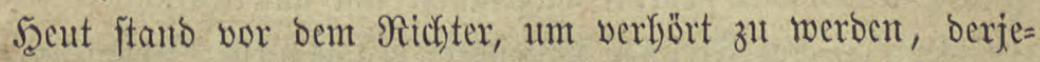

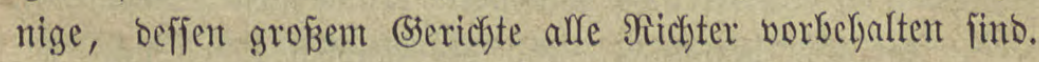
Sn biejer Nacht war bie Sonne ${ }^{3}$ ) cingeferfert, unt ange=

1) am Eharfreitage, an bem wabricheinlidy sicfe Rebe ge= Galten wurbe.

2) $\mathfrak{B o m}$ Domerstag alf ben Freitag.

3) Ehriftub, bie Sonne ber Seredjtigfeit. Mafady. IV, 2. 
flagt zu werben, warum fie über bie (siejchoppfe aufgebe uno biejerben erfeuchte. Seut trat bas Sicht ${ }^{1}$ ) fiutein, um vou

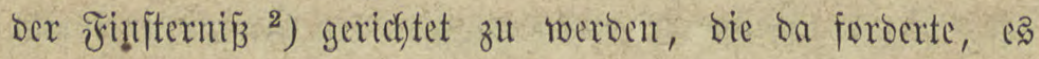
folfe nicht leuchten uno fie nicht erleuchtent. In biejer Nacht

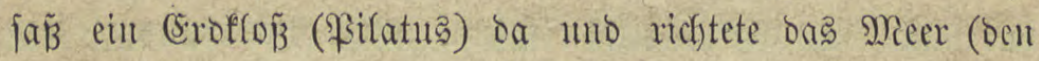

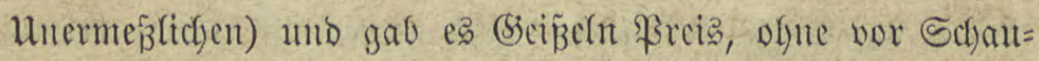

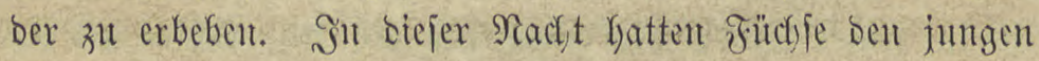
Sönent in's (Sefëngní̉ gemorfen uno wachten uno bemachtent

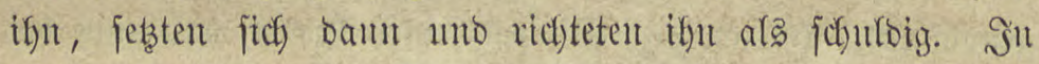
biefer Sacft magten Dornen ficl) frecf) an bas ghilgende Fener ${ }^{3}$ ), fpicen es an uno es rübrte ficl) nicht, um fie zu verzefren 4. . . 10.1

\section{Aus der liebenten Rede.}

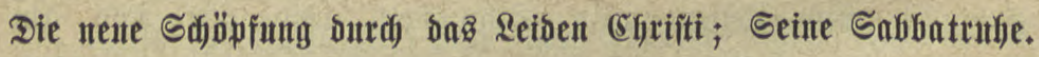

Betractenten wir nun bie neue Sdyopfung, bic oa ge= morben, und wie erftaunlicf bie Reiben maren, bie ifretne= gen ftattfanben! Echanen wir auf bas $\mathfrak{x e r t , ~ b a s ~ u n ~}$ burch Mälye bollforacht marb, uno fucken wir bort audf bie Auke, die bafür mohl geziemtello war! Der freitag war mit feinen seiben über ben erbabnen Errlöjer gefommen, ber Sonnabend ringegen rief iful zux Ruble, jeine Schmerzen zut vergeffent. $2\left(m\right.$ Sabbat volfendete er wie im $\mathfrak{A n f a n g}^{4}$ ) feine Werte, utio biejer fiebente Tag fübrte ifn auf liebricke 2 seife

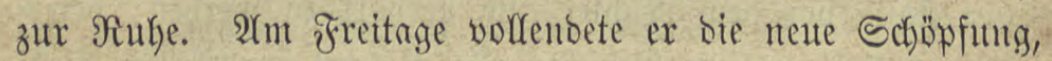
bie ex all ifym begonnell, und ber Eabbat fam, um dem

1) Sefus trat in bas serictstaknas.

2) Sut. XXII, 53. Finfterniß $=$ Rinber ber Finfterniß.

3) Sott wirb in ber hl. Sctyrift befanntlich bfter ein verzebrento Feuer gentant, z B. V. Mof. 4, 24. Seebr. XII, 29.

4) b. i. bei ber exften Schoppfung. 


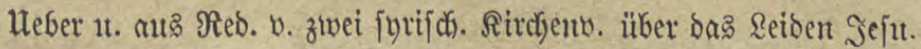

Ermatteten, ber ba fchlief, Nukge zu bringen. F̧⿻上丨 ging bas Whort in Erfüllung: "Der Serr ruhte am fieben= ten Iage", und biejes (Sicheimniffes megen ${ }^{1}$ ) berlyerrlichte Miofes den Eabbat. Dor Iang murbe fo bennmut, weil alt ifym bie \&aft ber Reiben aufförte uno ber şerr von jener

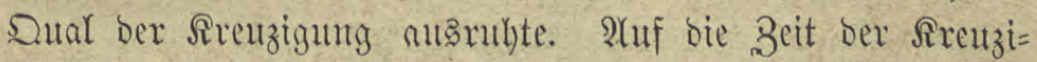
gung fchau, o Berjtänoiger, wenn bu faumft, verftänoig mie

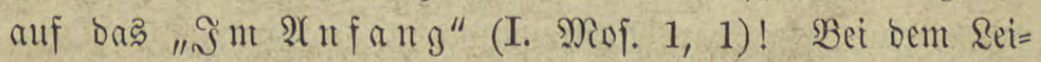
bent bes stutgebornten waro bie Echöpfung gleichfam em= pfangen, camit fie bas zweite Mal als neue geiftige (Sieburt baftefye. Das Seben vernichtete Den Iob burd) ben Too bes

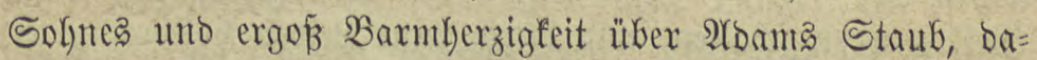
mit er gefammelt werbe. Durch ben Edfweiß unfers Seerrn

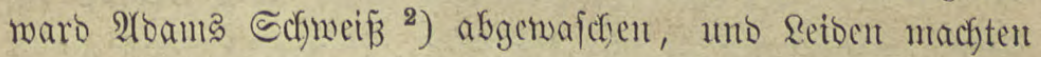
Dort bell Reiben ${ }^{3}$ ) eill Ende. Dur(i) bie Räget waro mit bem Starfent ${ }^{4}$ ) bie Sünbe angeheftet und burch feinte Freu=

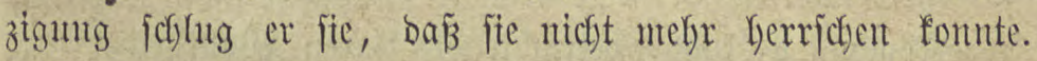
2refe bie Goken Miauern ber Anterwelt wurben zerftört, uno

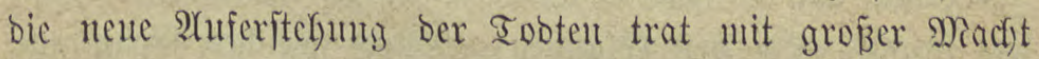
an's Richt. Die Weít ber Reiben ging burch bie Reiocnt bes Sokns unter, uno fie warb auf loodjerftaunliche Sacife eine

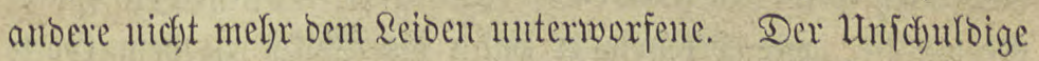
murbe anftatt ber Sofulbigen gefdrlagelt, 1 m fie burch feine

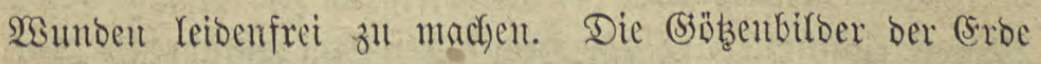

1) b. $t$. ber vorbirbenbenBebeutung wergen. Die $\Re$ the

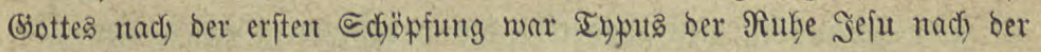
volforadjten neuen Scjöpfuntg.

2) zu bem er zur Strafe verurtheilt war. I. Mof. III, 19.

3) Seju Reiben entbetent bic Reiben ber fünbigen Mienfichen burch bic (Exlöjung von ber Sünbe unb emigen Strafe.

4) b. i. SGriftuts, ber bie Siffuldofdyrift unfrer Sünben an's Rrenz beftete. Eolofif. II, 14. 
murben als nichtig erwiejen, uno bie Schöpfung erbebte, um ifgre 2̂fggötter zum Bertrümmern nieber zu ftürzen.

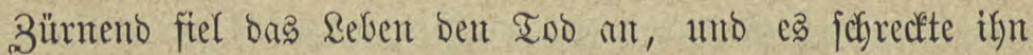
bie ungemöhnliche 2luferitehung ber Tobten. Gottes Eofn wiberitano mit Mackyt ben Seiben, uno tritg anjtatt bex Sünder bie Bürbe ber Schmerzen. (Ex müfte fich $a b$, bie Welt reich an (sütern zu machen, uno ging bann in bie

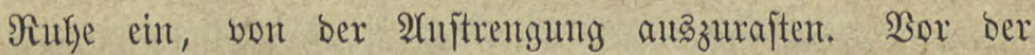
Sereuzigung war bie Schöpfung nodh ungeorbutet; nachoem

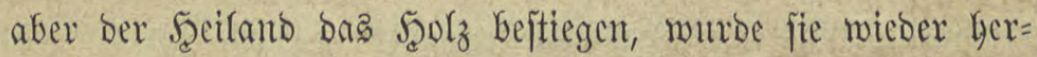
geitellt. Unjer Scerr hatte fich aufgemacht, butch Mübe dic siselt neu zu fdraffen, und burdh feine Reiben vollforachte ex

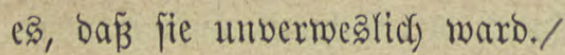

\section{Aus Der adjten Rede.}

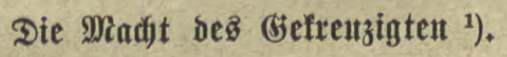

Romm, D Sube, Betradgte bie flaren Saafrbeiten uno

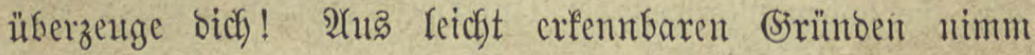

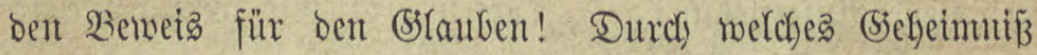
erff(ären wobl eure Refhrer ben herrlicken Iriumph biejes (Se= freuzigten unter ben Bölfern? Wsent berjelbe gegen bas Şaน (Gottes ift, wie befef)rte ex bann bie Sälfer zu bem Gotte

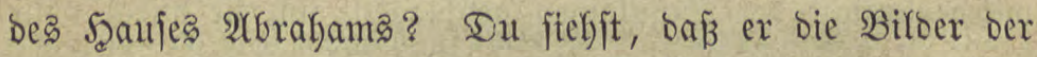

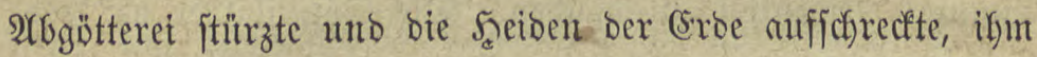
zu geforchen. (Er ftürzte bie vorker angebeteten Govle, machte

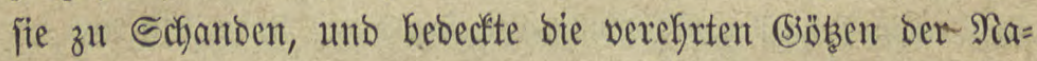

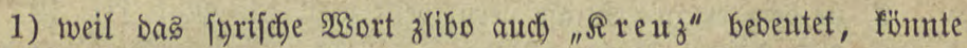
man "bes $\Omega$ reuzes" überjezen. Der Bufammentbang aber zeigt,

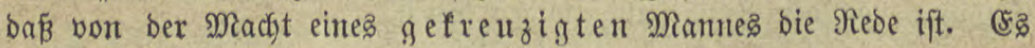
fommen 2 tusbrilde vor, bie auf bas STreuz fid nicht anwenden Yaffen.

Die Nebe ift an einen Suben gerichtet. 


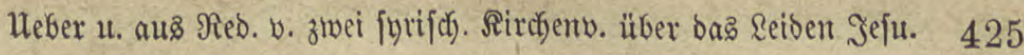

tionen mit Schmach. Bum (Siefpötte wurbent bie midftigen (Siebilbe, bie ber Böje aufgeftellt, unto bie Sceibent lachten über ben ganzen Sanfen ifgrer (Söbzen. WBie vermodfte ein gefreuzigter-Mann biép zu bemirten, uno burch wefdse Macfyt bänoigte er bie empörte Eroc? Die alten Fropheten beeiferten fich won Beit zu Beit jebr, bie abgöttif(f)en Bilber Der (Eroe zu zeritören, uno hatten is uicht vermocft. Mofes fämpfte burch Wander mit Rraft gegen 2(Yegysten, züchtigte e马 burch Pflagen ungemein, uno boch wurbe es nicht befefyrt

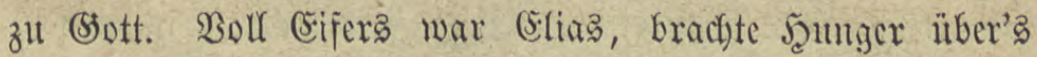
Sand und veröbete es, vollfühtrte neue Dinge, rief Feuev Gerab, machte Negen nieberjtrömen, ichlachtete bie Bfaffen

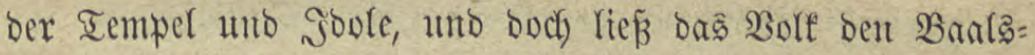
bienjt uicht fafyren ${ }^{1}$ ). WSie geborcht es num cinem reiben= ben Manne? Der (Sseflenzigte fant nicht wie Miofes mit

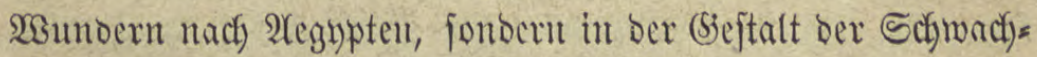
heit, bie ex angezogen hatte, unto obfdyon er nicht (siemalt

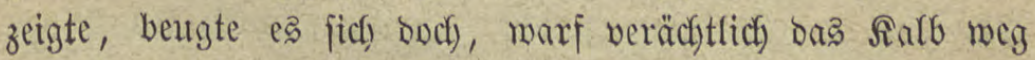

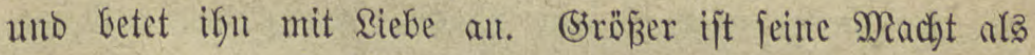
bie ber Sez̧ten uno Exjten; benu auf fanfte Weife bezmang

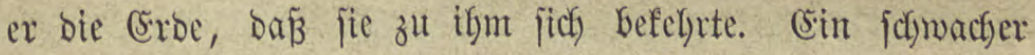
Mentich bätte bergleichen nicht berwirfen tömten. Raß̉ bich nicht beirren, baj er gefrenzigt ift, und verachte nicht feine

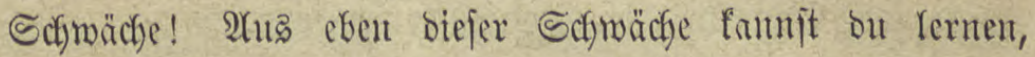

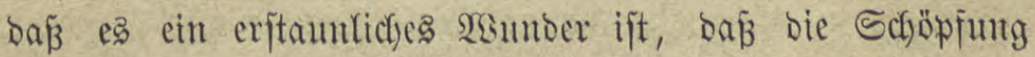
feine Sirnzigung füblte. Weil er ber Solgn des Schöpfers ift, Görte auf ifnt bie ganze Scföpfung, uno weil er anbe= tungsmöndig ijt, entrij er die ifm gebüfrende sigre ben

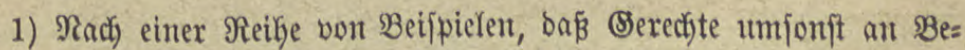
fehruitg ber Sdyledten arbeiten, fübrt er fort, wie oben fteht.

sheor. Quartalidifift. 1871. seft III. 


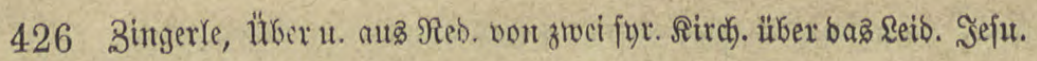

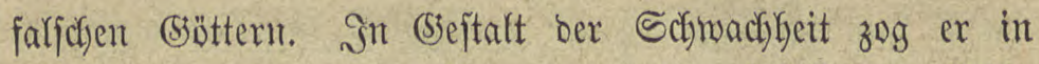
affe $\mathfrak{S e l t g e g e n d e n ~ a u s ~ u n d ~ u n t e r m a r f ~ f i c h ) ~ b i e j e l b e n ~ b e m u ̈ t f f i g ~}$ ofme Bsemalt. Silt bem (sinen 2tushruf, ben er laut am

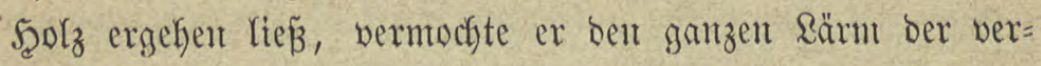
Derblicfent Fejte ber 24bgötterei zum Echweigen zu bringen.

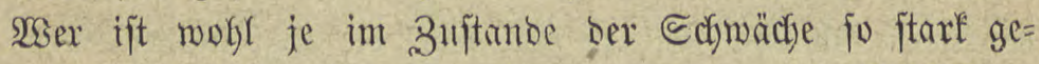
wejen und bat, whye Bicmalt alzuwenden, bie Echöpfung fich) unternourfen? Diejer ijt wahlyaft ber F̧err ber Welt uno lyat fich bieferfe zum (sigentfum erworben, jo bafis jie (iic) beugte ifnn anzubeten. Range Beit Katte fie vergeffen, wer ifjer Scerr fei; ars er fie aber befuchte, erinnerte fie (ic) mieber, zu ifm zurüdfulfefyren. Der Biffentzigte ging

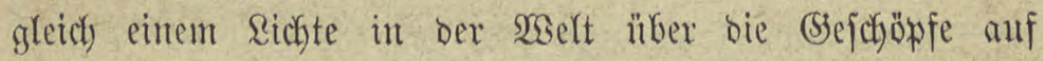
und reinigte beu Srseg vom Dunfer ber 2rogötterei. Durch

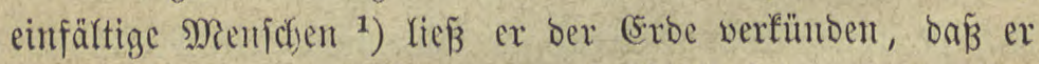
ify Şerr fei; da verftummte dab (sejchrei ber 2 seltweifen unb er triumplgite. Seiçst burch jiegreicfe Sämtpfer uno Wseife bat er fein Reich errichtet, fontocun burch Ungelebrte uno Unmiffende zeigte er feine Macht. Son 2rffem entblöste

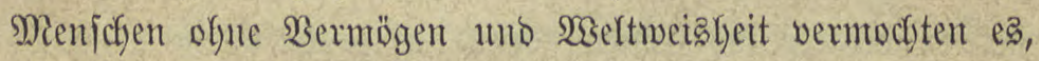

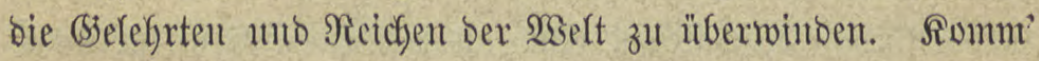

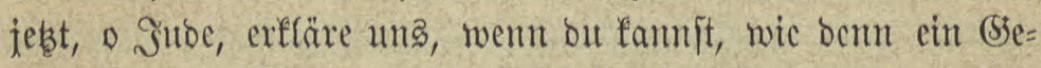
frenzigter im Stanbe war bießs zubemirfen! Wrie hat er im

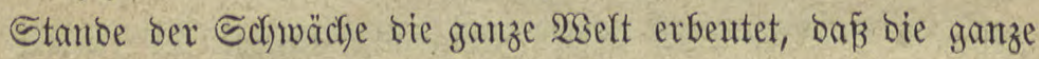
Schöpfurg zu feinter Rrenzigung bie Buffucht nimmt? u. f. f.

Bei ber Mittbeilung biejer Froben aub satob glaube

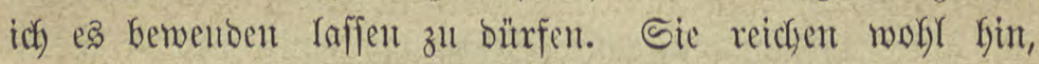
um feine Manier zu charafterifitelt, uno feine Berfchiebentyeit vom Stile Şaafs in's Sicft zu fetzen./

1) ungelebrte Fijdyer. I. Sorinth. 1, 26-29. 


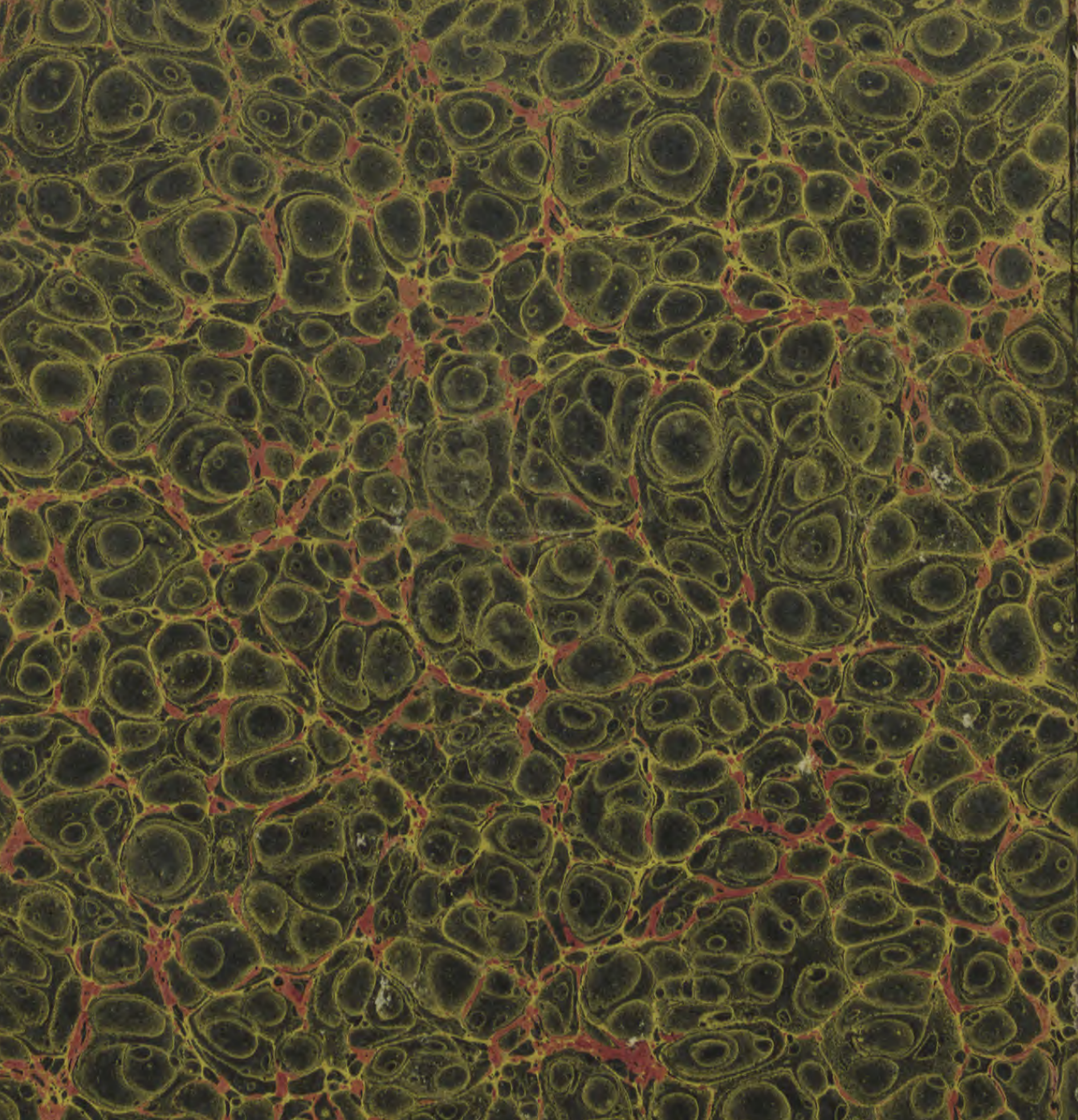

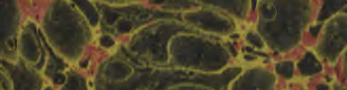

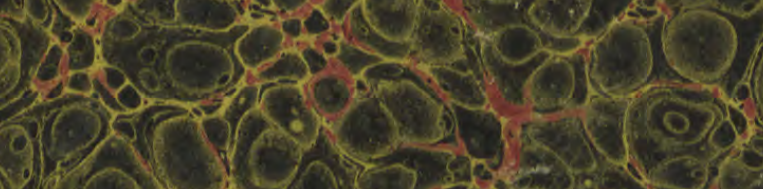

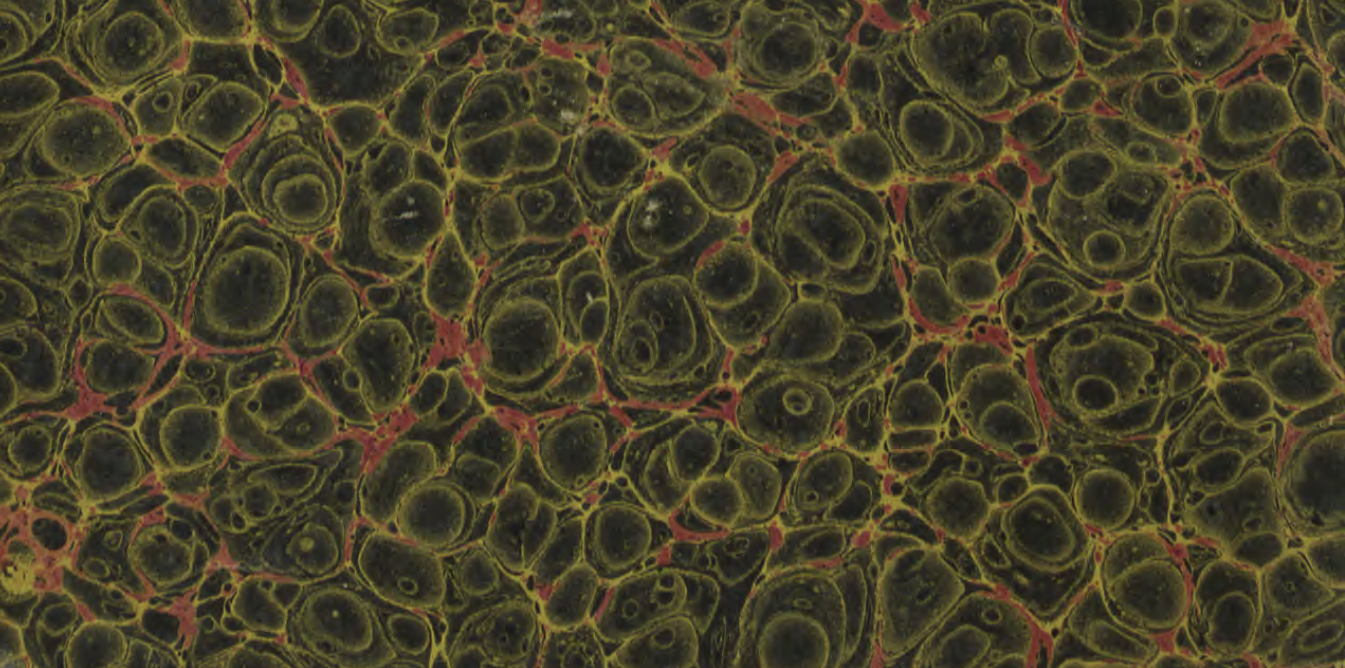

